\title{
Metastable and transient states of chemical ordering in Fe-V nanocrystalline alloys
}

\author{
T. Ziller and G. Le Caër* \\ Laboratoire de Science et Génie des Matériaux et de Métallurgie, U.M.R. C.N.R.S. 7584, Ecole des Mines, F-54042 Nancy cedex, France
}

O. Isnard

Laboratoire de Cristallographie du C.N.R.S., associé à l'Université Joseph Fourier, BP 166, F-38042 Grenoble cedex 9, France

P. Cénédèse

Centre d'Etudes de Chimie Métallurgique, U.P.R. C.N.R.S. 2801, 15 Rue Georges Urbain, F-94407 Vitry-sur-Seine cedex, France

B. Fultz

Division of Engineering and Applied Science, mail 138-78, California Institute of Technology, Pasadena, California 91125

(Received 23 July 2001; published 19 December 2001)

\begin{abstract}
Chemical ordering of the disordered alloys $\mathrm{Fe}_{0.78} \mathrm{~V}_{0.22}, \mathrm{Fe}_{0.53} \mathrm{~V}_{0.47}, \mathrm{Fe}_{0.39} \mathrm{~V}_{0.61}$, and $\mathrm{Fe}_{0.37} \mathrm{~V}_{0.63}$ was performed by annealing at temperatures from 723 to $973 \mathrm{~K}$. The initial state of chemical disorder was produced by high-energy ball milling, and the evolution of order was measured by neutron diffractometry and by ${ }^{57} \mathrm{Fe}$ Mössbauer spectrometry. The hyperfine magnetic field distributions obtained from the Mössbauer spectra provided quantitative measurements of the number of antisite $\mathrm{Fe}$ atoms in the partially ordered alloys. The long-range order parameters in steady state after long annealing times were used as states of metastable equilibrium for a generally successful comparison with the metastable $\mathrm{Fe}-\mathrm{V}$ phase diagram calculated by Sanchez et al. [Phys. Rev. B 54, 8958 (1996)]. For the metastable equilibrium state of order in $\mathrm{Fe}_{0.53} \mathrm{~V}_{0.47}$ at low temperatures, the order parameters were smaller than expected. This corresponded to an abundance of antisite atoms, which were not removed effectively by annealing at the lower temperatures.
\end{abstract}

DOI: 10.1103/PhysRevB.65.024204

\section{INTRODUCTION}

The equilibrium $\mathrm{Fe}-\mathrm{V}$ phase diagram ${ }^{1}$ shows complete mutual solubility of Fe and $\mathrm{V}$ in a bcc $\alpha$ phase at high temperatures, and shows a $\sigma$ phase below $\sim 1500 \mathrm{~K}$ in the central part of the diagram. Owing to the slow kinetics of the $\alpha \rightarrow \sigma$ transformation, the formation of $\sigma$-phase can be bypassed kinetically, and a disordered bcc phase can be obtained at low temperatures by rapid cooling. ${ }^{2}$ A chemical ordering transformation into an ordered $B 2$ phase $(\mathrm{CsCl}$ structure) can then occur on the bcc lattice during annealing at low temperatures. ${ }^{1-4}$ For example, a metastable $B 2$ phase has been prepared in $\mathrm{Fe}-\mathrm{V}$ alloys with equiatomic compositions by quenching from above $\sim 1500 \mathrm{~K}$, and annealing the unstable $\alpha$ phase for a few hours at $870 \mathrm{~K},{ }^{1-4}$ or for a few days at temperatures between 700 and $800 \mathrm{~K}^{4}$

Although the $B 2$ phase does not appear on the equilibrium phase diagram, a metastable $\mathrm{Fe}-\mathrm{V}$ phase diagram for the $A 2$ and $B 2$ phases, without $\sigma$ phase, has been calculated recently. ${ }^{4}$ The calculations were performed with the cluster variation method, using effective cluster interactions derived from experimental short-range order measurements. ${ }^{5}$ This metastable phase diagram, presented in Fig. 1, shows that the $A 2$ and $B 2$ phases and their two-phase admixture exist over broad ranges of composition. The phase boundaries are symmetrical about the equilibrium composition, since the cluster interactions were composition-independent (they were obtained from measurements on one composition). Approximate critical temperatures for the order-disorder transition $T_{c}$ were obtained from differential scanning calorimetry experiments on binary alloys and ternary alloys heated very rapidly. ${ }^{2}$ These measurements indicate that $T_{c}$ is a nearly
PACS number(s): 61.12.Ld, 81.30.Hd, 81.20.Ev, 76.80.+y

symmetric parabola in composition with a maximum at about $1140 \mathrm{~K}$ for the equiatomic composition. ${ }^{2}$ Because of the reduced atomic mobility, few experimental confirmations of the $A 2-B 2$ two-phase region below $\sim 750 \mathrm{~K}$ are available.

Mechanical alloying ${ }^{6,7}$ has been used to synthesize disor-

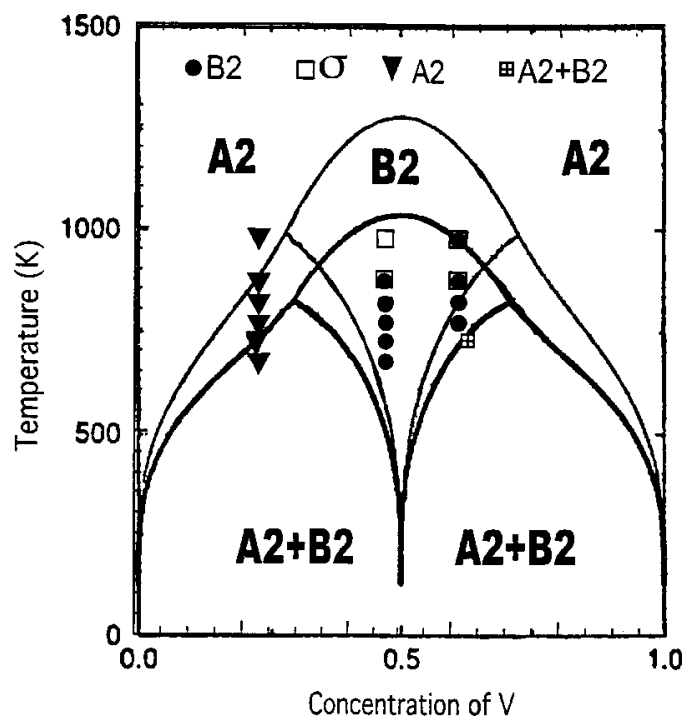

FIG. 1. Calculated metastable Fe-V phase diagram from Sanchez et al. (Ref. 4) together with the experimental results found in the present work for $\mathrm{Fe}_{0.78} \mathrm{~V}_{0.22}, \mathrm{Fe}_{0.53} \mathrm{~V}_{0.47}, \mathrm{Fe}_{0.39} \mathrm{~V}_{0.61}$, and $\mathrm{Fe}_{0.37} \mathrm{~V}_{0.63}$ [thin and thick lines are calculated from pairwise interactions deduced from experimental short-range order parameters measured at 1133 and $1473 \mathrm{~K}$, respectively (Ref. 5)]. Full triangles denote bcc, closed circles denote $B 2$, and squares denote $\sigma$ phase. 
dered bcc Fe-V alloys. ${ }^{8,9}$ Mechanically alloyed crystalline materials have consolidated grains with typical sizes of $\sim 10$ $\mathrm{nm}$. Their high density of defects, especially vacancies and grain boundaries, enhance the kinetics of ordering, enabling studies at lower temperatures and more practical times than have yet been achieved. The study of ordering in nanocrystalline alloys is itself a topic of widespread current interest. The formation of $B 2, L 1_{2}$, and $D 0_{3}$ order in several nanocrystalline alloys have been reported, including Ti-Al, Fe-Al, $\mathrm{Fe}-\mathrm{Si}, \mathrm{Fe}-\mathrm{Co}$, Ni-Al, and $\mathrm{Cu}-\mathrm{Au}$, sometimes with ternary additions. ${ }^{10-25}$ These studies have emphasized various aspects of defects and diffusion in nanostructured alloys, with comparisons to bulk materials. The reverse transformation, disordering a $\mathrm{B} 2$-ordered $\mathrm{Fe}_{60} \mathrm{Al}_{40}$ nanocrystalline alloy during high-energy ball milling, has also been studied recently. ${ }^{26}$

A number of features seem common to the reordering of chemically disordered nanocrystalline materials, in spite of differences in their methods of synthesis (e.g., ball milling, ${ }^{10,11,15,17-20,23,24,27}$ plastic deformation, ${ }^{28}$ gas-phase condensation with compaction, ${ }^{21,22}$ sputtering, ${ }^{16}$ ion irradiation $^{29}$ ), microstructures (isolated clusters ${ }^{16}$ or more typically micron-sized particles composed of nanometersized grains), and ordered structures. Reordering can occur at low temperatures, and involves only few jumps of nonequilibrium vacancies that were not promptly annihilated at sinks. ${ }^{17,21-24,28-30}$ Grain boundaries probably prevent order from propagating from one grain to another. ${ }^{15,19}$ It is less clear if chemical disorder exists near grain boundaries or antiphase boundaries (APB's).

A curious feature of ordered nanocrystals is that the steady-state value of the long-range order (LRO) parameter is generally lower than that of bulk samples. ${ }^{16,19,20-22}$ For example, the relative long-range order parameter of $\mathrm{Fe}_{0.53} \mathrm{Al}_{0.47}$ synthesized by gas-phase condensation and highpressure compaction, annealed at $800 \mathrm{~K}$ and below, stabilizes at 0.8 instead of increasing to $1.0 .^{21,22}$ It is not obvious if this suppressed order parameter is intrinsic to the nanocrystalline structure, or if it is a kinetic effect associated with the low temperatures of annealing.

Here we report results of an experimental investigation on the $B 2$ ordering of nanocrystalline bcc Fe- $\mathrm{V}$ alloys. Alloys of different composition were synthesized by mechanical alloying, and ordering was induced by annealing at low temperatures. Experimental measurements were performed with both neutron diffractometry and ${ }^{57} \mathrm{Fe}$ Mössbauer spectrometry. Quantitative LRO parameters were obtained from neutron diffractometry data, and reasonable LRO parameters were obtained from Mössbauer spectrometry. The agreement between these two LRO parameters gives confidence in our interpretations of the hyperfine magnetic field distributions (HMFD's) obtained from Mössbauer spectra. These HMFD's proved useful for measuring the number of antisite $\mathrm{Fe}$ atoms in partially ordered alloys. We found that the steady-state LRO parameter was lower than expected, owing to a large transient population of antisite defects. This antisite population correlates to the presence of APB's. We interpret this antisite population in the context of Monte Carlo simulations of ordering with a vacancy mechanism, which show the presence of excess antisite atoms during the motion of
APB's. ${ }^{31-33}$ Finally, over the course of this work, we used the steady-state order parameters to assess the boundaries of the $\mathrm{Fe}-\mathrm{V}$ metastable phase diagram.

\section{EXPERIMENT}

Sample preparation began with elemental powders of $\mathrm{Fe}$ $(99.9+\%,<10 \mu \mathrm{m})$ and V $(99.5 \%, 325 \mathrm{mesh})$. Three powder mixtures, $\mathrm{Fe}-25$ at. $\% \mathrm{~V}, \mathrm{Fe}-50$ at. $\% \mathrm{~V}$, and $\mathrm{Fe}-65$ at. \% $\mathrm{V}$, were milled for $12 \mathrm{~h}$ under an argon atmosphere in a steel vial with seven steel balls ( $16 \mathrm{~mm}$ diameter, $15 \mathrm{~g}$ each). The mill was a Fritsch Pulverisette 7 planetary ball mill operated with a disc rotation of $711 \mathrm{rpm}$. The powder: ball weight ratio was 1:20. During milling, iron from the vial and balls was incorporated into the samples, changing their compositions. The actual compositions of the as-milled samples were determined by chemical analysis to be $\mathrm{Fe}_{0.78} \mathrm{~V}_{0.22}$, $\mathrm{Fe}_{0.53} \mathrm{~V}_{0.47}$, and $\mathrm{Fe}_{0.39} \mathrm{~V}_{0.61}$. The final composition of another $\mathrm{Fe}-65$ at. $\% \mathrm{~V}$ mixture milled for only $4 \mathrm{~h}$ was $\mathrm{Fe}_{0.37} \mathrm{~V}_{0.63}$. The alloys were subsequently sealed under vacuum $\left(\approx 10^{-5} \mathrm{~Pa}\right)$ in quartz ampoules and annealed at temperatures ranging from 723 to $973 \mathrm{~K}$. The ampoules were quenched into water.

X-ray diffraction patterns were measured using Co $K_{\alpha 1}$ radiation $(\lambda=0.17889 \mathrm{~nm})$ with a $\theta-2 \theta$ powder diffractometer. Neutron diffraction patterns $(\lambda=0.128$ and $0.252 \mathrm{~nm})$ were measured with the D1B multicounter instrument at ILL (Grenoble). Lattice parameters were determined by Rietveld refinement with the software package FULLPROF. ${ }^{34}$ The Warren-Averbach method ${ }^{35,36}$ was used to obtain the rootmean-squared strain and the sizes of the crystallites.

Iron-57 Mössbauer spectra were measured at room temperature (RT) and at $8 \mathrm{~K}$ in transmission geometry with a spectrometer operated in the conventional constantacceleration mode. The source was ${ }^{57} \mathrm{Co}$ in $\mathrm{Rh}$ with a strength of $\sim 10 \mathrm{mCi}$. The magnetic components of spectra were analyzed as overlapping sextets of Lorentzian lines, using a conventional constrained Hesse-Rübartsch method ${ }^{37}$ to obtain the sextet splittings and shifts, and hence as HMFD's, $P(B)$. It was assumed that isomer shift $I S(B)$ varies linearly with $B$ with a typical slope of 7 $\times 10^{-3} \mathrm{~mm} \mathrm{~s}^{-1} \mathrm{~T}^{-1}$.

\section{RESULTS}

\section{A. X-ray diffractometry}

$\mathrm{X}$-ray diffraction patterns were measured at room temperature for $\mathrm{Fe}_{0.78} \mathrm{~V}_{0.22}, \mathrm{Fe}_{0.53} \mathrm{~V}_{0.47}$ and $\mathrm{Fe}_{0.39} \mathrm{~V}_{0.61}$ alloys annealed for various times at temperatures ranging from 723 to $973 \mathrm{~K}$. These data were not useful for determining longrange order parameters - the $\mathrm{x}$ ray form factors of $\mathrm{Fe}$ and $\mathrm{V}$ are so similar that concentration waves of $\mathrm{Fe}$ and $\mathrm{V}$ contributed negligible intensity to superlattice diffractions. After annealing, it was nevertheless possible to measure shifts of fundamental bec Bragg diffractions towards higher $2 \theta$ angles, indicating a decrease of lattice parameter. Figure 2(a) shows the lattice parameter evolution with annealing time at $723 \mathrm{~K}$ for $\mathrm{Fe}_{0.78} \mathrm{~V}_{0.22}$ and $\mathrm{Fe}_{0.53} \mathrm{~V}_{0.47}$. From correlations with other data, we believe these decreases in lattice parameter are primarily a consequence of ordering in the alloys, but some 

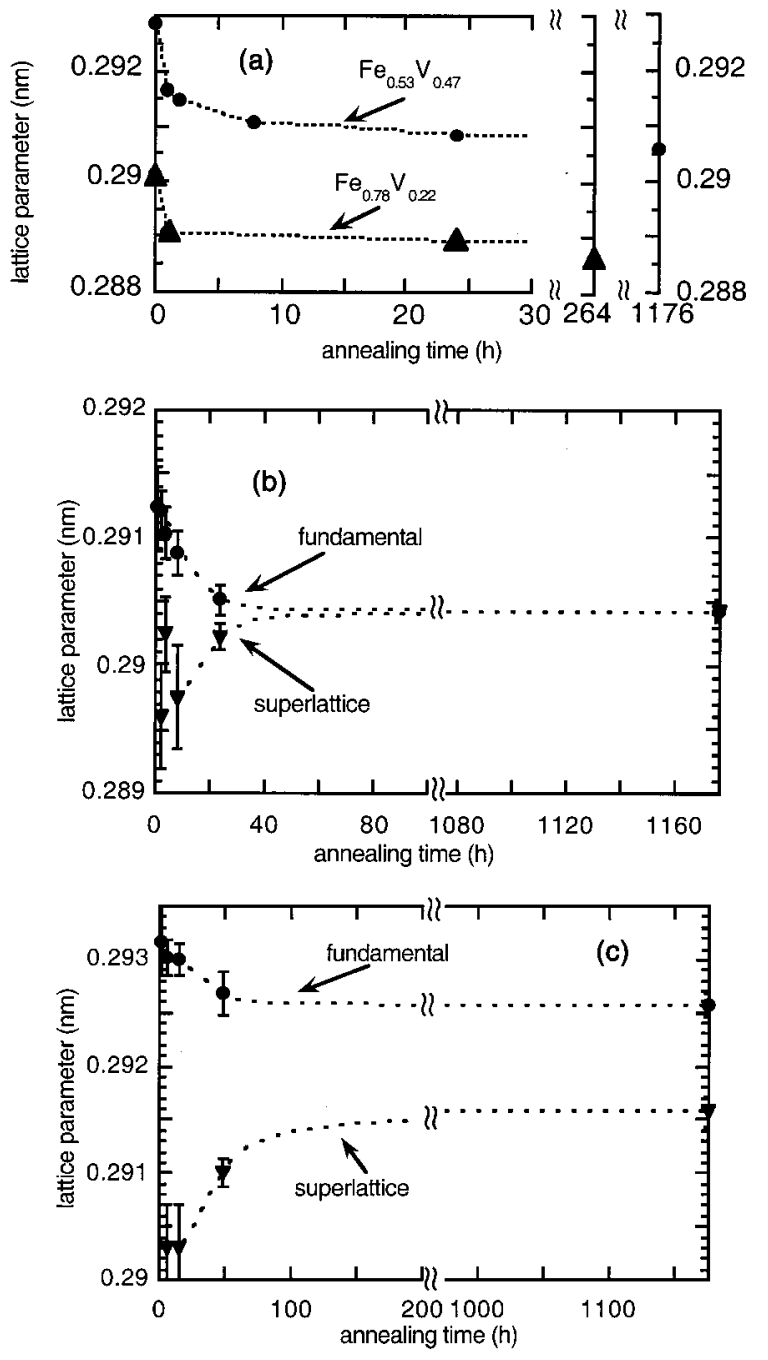

FIG. 2. Room temperature lattice parameter as a function of annealing time at $723 \mathrm{~K}$ : (a) for $\mathrm{Fe}_{0.78} \mathrm{~V}_{0.22}$ (full triangles) and $\mathrm{Fe}_{0.53} \mathrm{~V}_{0.47}$ (full circles) from x-ray diffraction patterns, (b) for $\mathrm{Fe}_{0.53} \mathrm{~V}_{0.47}$ from fundamental (full circles) and from superlattice (full triangles) peaks of neutron diffraction patterns, (c) for $\mathrm{Fe}_{0.37} \mathrm{~V}_{0.63}$ from fundamental (full circles) and from superlattice (full triangles) peaks of neutron diffraction patterns.

of the decrease could be caused by the loss of interstitial atoms $(\mathrm{Ar}, \mathrm{O}, \mathrm{N}, \ldots$ ) or the oxidation (or nitriding) of a small fraction of the sample.

Lattice parameters often decrease upon ordering in alloys, ${ }^{38,39}$ and the lattice contraction can be proportional to the change in LRO parameter $S$, specifically. $\left(a-a_{\text {ord }}\right) / a_{\text {ord }}$ $\propto(1-S) .{ }^{39}$ On the other hand, the lattice parameter of
$\mathrm{Fe}_{0.78} \mathrm{~V}_{0.22}$ decreases even though no long-range ordering occurs during annealing (see below). Furthermore, the lattice parameters of the as-milled alloys are $\sim 1 \%$ larger than those of disordered alloys of the same compositions prepared by conventional ingot metallurgy, ${ }^{40}$ as given in Table I. This could be caused by a smaller amount of chemical short-range order (SRO) in the ball-milled material. The large lattice parameters in alloys disordered by milling have generally been attributed to the formation of antisite defects as proposed for $B 2 \mathrm{FeAl},{ }^{19-22,41}$ but a high density of APB's could have a similar effect. A lattice expansion from interstitial atoms introduced from adsorption on the surfaces of the initial powders cannot be ruled out entirely. The decrease in lattice parameter tracks well the reduction in order parameters, however, and this is unexpected if the interstitial atoms are removed by the precipitation of oxides or nitrides, for example. A small amount of vanadium nitride $\mathrm{V}_{2} \mathrm{~N}$ was detected in X-ray diffraction patterns of $\mathrm{Fe}_{0.39} \mathrm{~V}_{0.61}$ annealed for $111 \mathrm{~h}$ at $773 \mathrm{~K}$, however.

$\mathrm{X}$-ray (and neutron) diffractometry shows the formation of equilibrium $\sigma$ phase in $\mathrm{Fe}_{0.53} \mathrm{~V}_{0.47}$ and $\mathrm{Fe}_{0.39} \mathrm{~V}_{0.61}$ samples after annealing for long times (100 and $200 \mathrm{~h}$, respectively) at the relatively high temperature of $873 \mathrm{~K}$. Although the formation of $\sigma$ phase is relatively sluggish, it is in fact much faster in these nanocrystalline Fe- $\mathrm{V}$ alloys than in coarsegrained $\mathrm{Fe}-\mathrm{V}$. In a conventional coarse-grained $\mathrm{Fe}_{0.50} \mathrm{~V}_{0.50}$ alloy annealed for $120 \mathrm{~h}$ at $873 \mathrm{~K}, \sigma$ phase forms only near free surfaces, and negligibly in the bulk. ${ }^{4,42}$ The $\sigma$ phase in our nanocrystalline Fe-V alloys formed from the $B 2$ phase. A crystallographic model for the transformation of a $B 2$ phase into a $\sigma$ phase was proposed long ago for $\mathrm{Fe}-\mathrm{V}$ alloys, ${ }^{43}$ and a $\sigma$-phase transformation through an intermediate $B 2$ phase was observed when a coarse-grained alloy was annealed at $973 \mathrm{~K} .{ }^{42}$ Evidently the kinetics of $\sigma$-phase formation is enhanced by the high density of nucleation sites at grain boundaries in nanocrystalline Fe-V alloys. (Enhanced kinetics of $\sigma$-phase formation was also reported in nanocrystalline $\mathrm{Fe}-\mathrm{Cr}$ and $\mathrm{Fe}-\mathrm{Cr}-\mathrm{Sn}$ alloys. ${ }^{44}$ ) The $\sigma$ phase was not observed after the annealing of nanocrystalline $\mathrm{Fe}_{0.78} \mathrm{~V}_{0.22}$, as expected from the equilibrium phase diagram.

\section{B. Neutron diffractometry}

\section{Order parameters}

The Bragg-Williams LRO parameter $S$ depends on the alloy composition $x$ of a $\mathrm{Fe}_{1-x} \mathrm{~V}_{x}$ alloy. For the $B 2(\mathrm{CsCl})$ structure, $S$ is

$$
S=2\left([\mathrm{Fe}]_{\mathrm{Fe}}-1+x\right),
$$

TABLE I. X-ray lattice parameters, strain distributions, and crystallite sizes of as-milled Fe-V alloys.

\begin{tabular}{ccccc}
\hline \hline Composition & $\begin{array}{c}\text { Lattice parameter, } \\
a(\mathrm{~nm})\end{array}$ & $\begin{array}{c}\Delta a \text { with respect to } \\
\text { Refs. 40, 51 (nm) }\end{array}$ & $\begin{array}{c}\text { rms strain }\left[\sqrt{\varepsilon^{2}}\right] \\
(\%)\end{array}$ & $\begin{array}{c}\text { Crystal size, } \\
d(\mathrm{~nm})\end{array}$ \\
\hline $\mathrm{Fe}_{0.78} \mathrm{~V}_{0.22}$ & $0.2901 \pm 0.0001$ & 0.0014 & 0.4 & 11 \\
$\mathrm{Fe}_{0.53} \mathrm{~V}_{0.47}$ & $0.2929 \pm 0.0001$ & 0.0017 & 0.4 & 6 \\
$\mathrm{Fe}_{0.39} \mathrm{~V}_{0.61}$ & $0.2955 \pm 0.0001$ & 0.0024 & 0.4 & 13 \\
\hline \hline
\end{tabular}


where $[X]_{Y}(X, Y=\mathrm{Fe}, \mathrm{V})$ is the concentration of atomic species $X$ on sublattice $Y$, where the designation $Y$ for the sublattice refers to its majority species. The LRO parameter is $S=0$ when the alloy is fully disordered. The maximum value of $S$ is $S_{m} \equiv 1-2|\Delta x|$, where $\Delta x \equiv x-0.5$. The concentration of vacancies is assumed to be negligible.

Diffraction patterns of disordered bcc Fe- $\mathrm{V}$ alloys include only fundamental $(h, k, l)$ diffractions for which the sum $h$ $+k+l$ is even, while patterns of Fe-V alloys with $B 2$ order also include superlattice diffractions for which $h+k+l$ is odd. The structure factor for the fundamental diffractions is $F_{f}$, and that of the superlattice diffractions is $F_{s}$ :

$$
\begin{gathered}
F_{f}(h k l)=2 \bar{u}(\theta) \bar{f}, \\
\left.\left.F_{s}(h k l)=2 \bar{u}(\theta)\left([\mathrm{Fe}]_{\mathrm{Fe}}-1+x\right)\right) f_{\mathrm{Fe}}-f_{\mathrm{v}}\right),
\end{gathered}
$$

where $f_{j}$ is either the atomic form factor (for x-rays) (Ref. 36 ) or the neutron coherent scattering length of atom type $j$, typically denoted $b_{j}$. Here $\bar{f}$ is an average form factor,

$$
\bar{f}=(1-x) f_{\mathrm{Fe}}+x f_{\mathrm{v}},
$$

and $\bar{u}(\theta)$ is the Debye-Waller amplitude,

$$
\bar{u}(\theta)=\exp \left(-\frac{\bar{B} \sin ^{2} \theta}{\lambda^{2}}\right)
$$

where $2 \bar{B}$ is $(4 \pi)^{2}$ times the mean-squared atomic displacement and $\lambda$ the wavelength. (A thermal atomic displacement factor, $\bar{B}=2.8 \times 10^{-3} \pm 0.04 \mathrm{~nm}^{2}$, was determined from the neutron diffraction pattern of the annealed $\mathrm{Fe}_{0.78} \mathrm{~V}_{0.22}$ alloy using FULLPROF. ${ }^{34}$ The intensities of the superlattice diffractions are proportional to $\left|F_{s}\right|^{2} \propto\left|f_{\mathrm{Fe}}-f_{\mathrm{v}}\right|^{2}$. Since the x-ray form factors for iron and vanadium atoms are very similar, the $\mathrm{x}$-ray superlattice diffraction intensities are nearly zero and $S$ cannot be measured reliably by x-ray diffractometry. In contrast, the neutron coherent scattering lengths of the two elements differ significantly. ${ }^{45} b_{\mathrm{Fe}}=9.45 \times 10^{-15} \mathrm{~m}$ and $b_{\mathrm{v}}$ $=-0.3824 \times 10^{-15} \mathrm{~m}$, making neutron diffractometry an effective method for measuring the chemical order of $\mathrm{Fe}-\mathrm{V}$ alloys.

The intensity of a diffraction peak also depends on $2 \theta$ angle through the Lorentz factor ${ }^{36} L(\theta)=(\sin 2 \theta \sin \theta)^{-1}$, and multiplicity of the diffracting planes, $m_{h k l}$. The LRO parameter is then obtained from the ratio of the integrated intensity $I^{s}$ of a superlattice peak to the intensity $I^{f}$ of a fundamental peak as:

$$
S^{2}=\frac{\left.4 I^{s} \bar{u}\left(\theta^{f}\right)\right)^{2}|\bar{b}|^{2} L^{f}(\theta) m^{f}}{I^{f} \bar{u}\left(\theta^{s}\right)^{2}\left|b_{\mathrm{Fe}}-b_{\mathrm{v}}\right|^{2} L^{s}(g v) m^{s}},
$$

where the superscripts $f$ and $s$ refer to the fundamental and the superlattice diffraction peaks.

A small magnetic contribution was added to the neutron structure factor. This contribution includes a $\theta$ dependence from the magnetic form factor of iron, and is proportional to the atomic magnetic moment. Table II presents some magnetic contributions to the intensity of the (110) Bragg peak for disordered bcc Fe-V alloys, calculated with the FULLPROF
TABLE II. Mean magnetic moment per $\mathrm{Fe}$ atom in the disordered $A 2$ phase and in the ordered $B 2$ phase of some Fe-V alloys from Ref. 46, and contribution of magnetic diffraction to the total intensity of the (110) Bragg peak of the $A 2$ phase.

\begin{tabular}{lcc}
\hline \hline Composition & $\left\langle\mu_{\mathrm{Fe}}\right\rangle\left(\mu_{B} / \mathrm{Fe}\right.$ atom $)$ & $\begin{array}{c}\text { Magnetic contribution } \\
\text { to the }(110) \text { Bragg peak } \\
(\%)\end{array}$ \\
\hline $\mathrm{Fe}_{0.798} \mathrm{~V}_{0.202}$ & $2.012(A 2)$ & 6 \\
$\mathrm{Fe}_{0.53} \mathrm{~V}_{0.47}$ & $1.126(A 2)$ & 2 \\
$\mathrm{Fe}_{0.382} \mathrm{~V}_{0.618}$ & $0.922(B 2)$ & 0.06 \\
& $0.584(A 2)$ & \\
\hline \hline
\end{tabular}

computer $\operatorname{code}^{34}$ by using the mean atomic magnetic moments measured by Nevitt and Aldred. ${ }^{46}$ The magnetic contributions are smaller in the ordered alloys because the mean magnetic moment decreases significantly when the alloy orders. ${ }^{46-49}$ An amorphous phase is seen in diffraction patterns of $\mathrm{Fe}_{0.53} \mathrm{~V}_{0.47}$ [Fig. 3(a)], $\mathrm{Fe}_{0.39} \mathrm{~V}_{0.61}$ and $\mathrm{Fe}_{0.37} \mathrm{~V}_{0.63}$ [Fig. 3(b)], for instance, between $2 \theta$ angles of $\sim 33^{\circ}$ and $\sim 42^{\circ}$, both in as-milled materials and in materials annealed for short times. This amorphous contribution was used to correct the shape of the background.

\section{Neutron diffractometry results on $\mathrm{Fe}_{0.53} \mathrm{~V}_{0.47}$}

To follow the ordering kinetics in $\mathrm{Fe}_{0.53} \mathrm{~V}_{0.47}$, neutron diffraction patterns were measured at room temperature on samples annealed at $723 \mathrm{~K}$ for 1-1176 h. The diffraction patterns show a gradual appearance of superlattice diffraction peaks [Fig. 3(a)]. With increased annealing time, these superlattice diffractions, which are very broad initially, narrow progressively and increase in integrated intensity. To obtain order parameters for the metastable steady state at the higher temperatures of 773 and at $823 \mathrm{~K}$, measurements were performed only on samples annealed for long times (100$200 \mathrm{~h}$ ). Although the annealings at $873 \mathrm{~K}$ were performed for short times to suppress $\sigma$-phase formation, ordering was quite rapid at this temperature and it was not possible to follow the kinetic evolution of order. The $B 2$ ordering also occurs at 773,823 , and $873 \mathrm{~K}$. Small, broad diffraction peaks from the $\sigma$-phase are visible after annealing for $5 \mathrm{~h}$ at $873 \mathrm{~K}$, and the alloy annealed for $100 \mathrm{~h}$ at $873 \mathrm{~K}$ is fully transformed into $\sigma$ phase. At $973 \mathrm{~K}$, the sample is fully $\sigma$ phase after annealing for only $30 \mathrm{~min}$.

The LRO parameter $S$ was obtained by comparing the integrated intensities of the (100) superlattice diffraction and the (110) fundamental diffraction by using Eqs. (1)-(6). Similar values of $S$ were obtained from other pairs of diffraction peaks. Figure 4 presents the LRO parameter as a function of annealing time at $723 \mathrm{~K}$ and other temperatures. At $723 \mathrm{~K}, S$ increases rapidly at first, and reaches a plateau between 8 and $24 \mathrm{~h}$. At higher temperatures, the annealing times of 100 and $200 \mathrm{~h}$ at higher temperatures should be more than sufficient to ensure a steady state of $B 2$ LRO parameter.

Figure 2(b) presents the lattice parameters of samples annealed at $723 \mathrm{~K}$ obtained from the positions of the funda- 
(a)

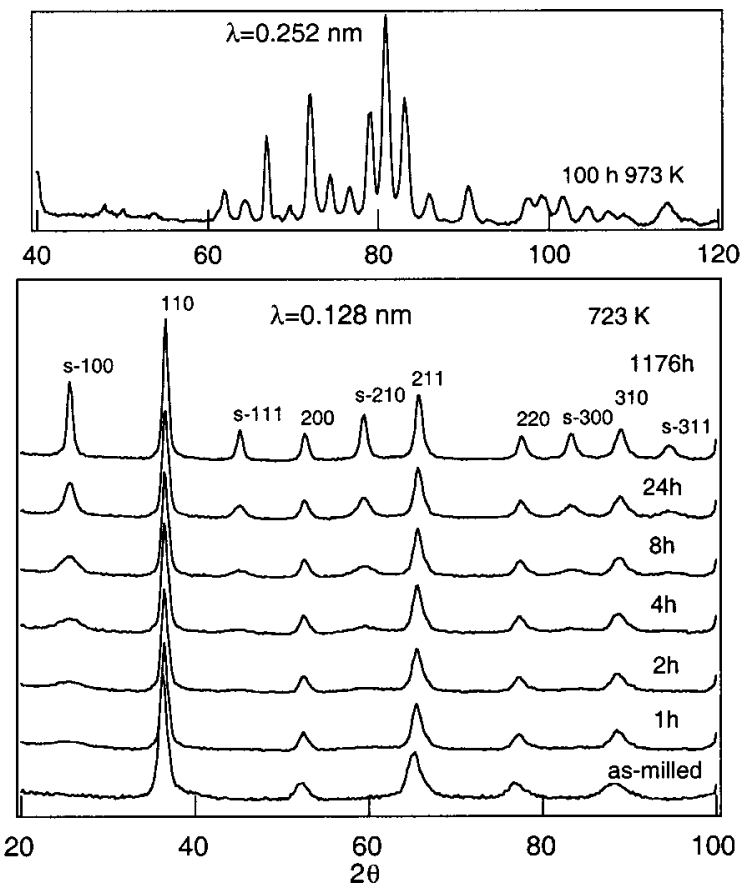

(b)

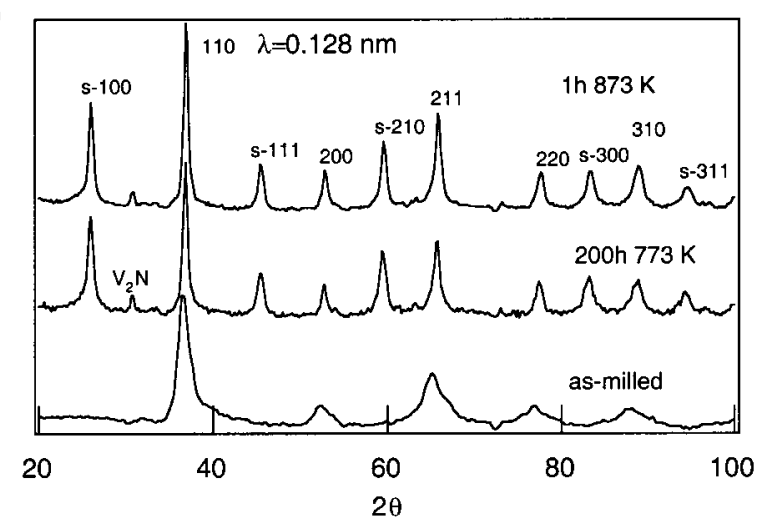

(c)

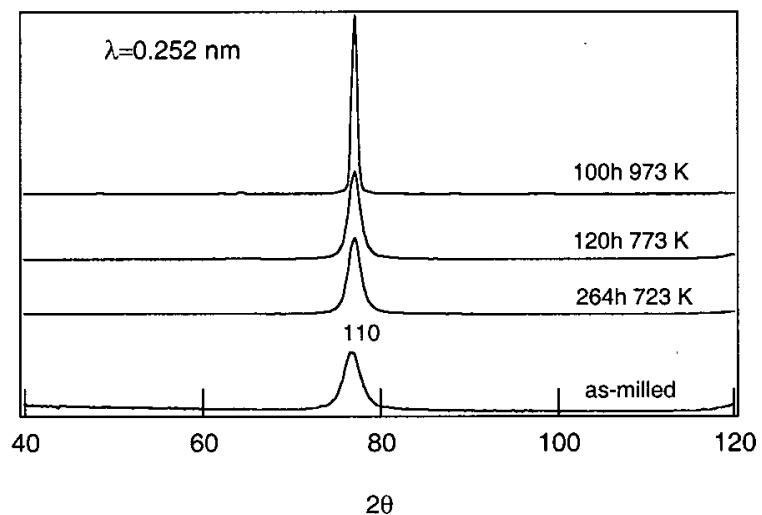

FIG. 3. Room-temperature neutron diffraction patterns of Fe-V alloys annealed for various times at temperatures ranging between 723 and $973 \mathrm{~K}$ ("s" stands for superlattice): (a) $\mathrm{Fe}_{0.53} \mathrm{~V}_{0.47}$ (b) $\mathrm{Fe}_{0.39} \mathrm{~V}_{0.61}$ and $\mathrm{Fe}_{0.37} \mathrm{~V}_{0.63}$, (c) $\mathrm{Fe}_{0.78} \mathrm{~V}_{0.22}$.

mental peaks $\left(a_{f}\right)$, and the superlattice peaks $\left(a_{s}\right)$. The lattice parameter $a_{f}$ is a lattice parameter averaged over the whole alloy, whereas $a_{s}$ is the lattice parameter from the ordered domains only. These two lattice parameters would be

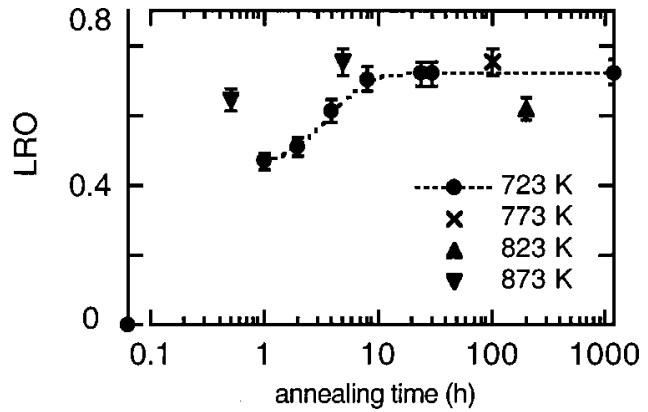

FIG. 4. LRO parameter of $\mathrm{Fe}_{0.53} \mathrm{~V}_{0.47}$ measured at room temperature as a function of annealing time at different temperatures.

equal for an homogeneously ordered alloy. In agreement with the results from x-ray diffractometry, $a_{f}$ decreases steadily with annealing time to reach the lattice parameter of the ordered domains after $\sim 50 \mathrm{~h}$. The $\mathrm{x}$-ray lattice parameter was slightly larger than $a_{f}$ from neutron diffractometry for all measurements at $773 \mathrm{~K}$ with a difference decreasing with annealing time. The difference in $a_{f}$ may arise because $\mathrm{Fe}$ atoms scatter neutrons more strongly than $\mathrm{V}$, and the local interatomic separations in Fe-rich regions differ from those of V-rich regions. The neutron diffraction patterns therefore tend to emphasize regions that are Fe rich, and therefore provide a smaller lattice parameter because $\mathrm{Fe}$ has the smaller metallic radius. This difference becomes smaller as ordering occurs, and the alloy becomes more homogeneous at the length scale of the unit cell. The mean sizes of crystallites and sizes of ordered domains were obtained with the Scherrer method from the widths of the (100) and (110) peaks [Fig. 4(a)]. The very small size of the ordered domains in the as-milled $\mathrm{Fe}_{0.53} \mathrm{~V}_{0.47}$ is comparable to the $2.5 \mathrm{~nm}$ domain size reported for ball-milled $B 2 \mathrm{FeAl}^{23}$ At $723 \mathrm{~K}$, the ordered domain size increases with annealing time and matches the crystallite size after some hundreds of hours. At higher temperatures, the size of ordered domains was equal to the crystallite size for the measured annealing times. These results show that the metastable steady state of $\mathrm{Fe}_{0.53} \mathrm{~V}_{0.47}$ alloy is in the $B 2$ single-phase region between 723 and $873 \mathrm{~K}$, as opposed to a disordered bcc alloy or a mixture of bcc and $B 2$ phase.

\section{Neutron diffractometry results on $F e_{0.78} V_{0.22}, F e_{0.53} V_{0.47}$, $\mathrm{Fe}_{0.39} \mathrm{~V}_{0.61}$, and $\mathrm{Fe} \mathrm{e}_{0.37} \mathrm{~V}_{0.63}$}

Neutron diffraction patterns show that $\mathrm{Fe}_{0.39} \mathrm{~V}_{0.61}$ and $\mathrm{Fe}_{0.37} \mathrm{~V}_{0.63}$ develop $B 2$ order after annealing at temperatures from 723 to $973 \mathrm{~K}$ [Fig. 3(b) and Table III]. The $\sigma$ phase appears after annealing for $200 \mathrm{~h}$ at $873 \mathrm{~K}$, but after only 30 min at $973 \mathrm{~K}$. Figure 2(c) shows the lattice parameters $a_{f}$ and $a_{s}$ (defined in Sec. III B 2) for the $\mathrm{Fe}_{0.37} \mathrm{~V}_{0.63}$ alloy annealed at $723 \mathrm{~K}$. The steady-state value of $a_{f}$ is larger than that of $a_{s}$. Further, the steady-state size of ordered domains $(5.5 \mathrm{~nm})$, measured after annealing for $1176 \mathrm{~h}$ at $723 \mathrm{~K}$, is smaller than the steady-state size of the crystallites $(8 \mathrm{~nm})$ [Fig. 5(b)]. These results on lattice parameter and domain size are consistent with a metastable coexistence of a disordered bcc phase and an ordered $B 2$ phase in $\mathrm{Fe}_{0.37} \mathrm{~V}_{0.63}$ at 
TABLE III. Experimental LRO parameter for $\mathrm{Fe}_{0.53} \mathrm{~V}_{0.47}$, $\mathrm{Fe}_{0.39} \mathrm{~V}_{0.61}$ and $\mathrm{Fe}_{0.37} \mathrm{~V}_{0.63} B 2$ alloys (the maximum LRO parameters for these alloys at $0 \mathrm{~K}$ are $S_{m}=0.94,0.78,0.74$, respectively)

\begin{tabular}{|c|c|c|}
\hline Alloy & Annealing treatment & $S$ \\
\hline \multirow{9}{*}{$\mathrm{Fe}_{0.53} \mathrm{~V}_{0.47}$} & as-milled & 0 \\
\hline & $1 \mathrm{~h}$ at $723 \mathrm{~K}$ & 0.47 \\
\hline & $2 \mathrm{~h}$ at $723 \mathrm{~K}$ & 0.51 \\
\hline & $4 \mathrm{~h}$ at $723 \mathrm{~K}$ & 0.61 \\
\hline & $8 \mathrm{~h}$ at $723 \mathrm{~K}$ & 0.70 \\
\hline & $24 \mathrm{~h}$ at $723 \mathrm{~K}$ & 0.72 \\
\hline & $1176 \mathrm{~h}$ at $723 \mathrm{~K}$ & 0.72 \\
\hline & $100 \mathrm{~h}$ at $773 \mathrm{~K}$ & 0.75 \\
\hline & $200 \mathrm{~h}$ at $823 \mathrm{~K}$ & 0.62 \\
\hline \multirow{10}{*}{$\mathrm{Fe}_{0.39} \mathrm{~V}_{0.61}$} & $35 \mathrm{~min}$ at $873 \mathrm{~K}$ & 0.64 \\
\hline & $5 \mathrm{~h}$ at $873 \mathrm{~K}$ & 0.75 \\
\hline & as-milled & 0 \\
\hline & $200 \mathrm{~h}$ at $773 \mathrm{~K}$ & 0.52 \\
\hline & $200 \mathrm{~h}$ at $823 \mathrm{~K}$ & 0.70 \\
\hline & $30 \mathrm{~min}$ at $873 \mathrm{~K}$ & 0.50 \\
\hline & $1 \mathrm{~h}$ at $873 \mathrm{~K}$ & 0.53 \\
\hline & $200 \mathrm{~h}$ at $873 \mathrm{~K}$ & 0.67 \\
\hline & $30 \mathrm{~min}$ at $973 \mathrm{~K}$ & 0.66 \\
\hline & $1176 \mathrm{~h}$ at $723 \mathrm{~K}\left(\mathrm{Fe}_{0.37} \mathrm{~V}_{0.63}\right)$ & 0.61 \\
\hline
\end{tabular}

$723 \mathrm{~K}$. For $\mathrm{Fe}_{0.37} \mathrm{~V}_{0.63}$, the metastable phase diagram calculated by Sanchez et al. ${ }^{4}$ does show a two-phase region of the $B 2$ ordered phase (with $57-60$ at. \% V) plus a disordered bcc phase (with 75-85 at. \% V). The difference between the lattice parameters of these two phases, $a_{\mathrm{bcc}}-a_{B 2} \sim 0.04 \mathrm{~nm}$, cannot be simply compared with the measured difference, $a_{f}-a_{s} \sim 0.001 \mathrm{~nm}$, because $a_{f}$ is actually the result of a complex averaging over coherent bcc and $B 2$ regions. Figure 3(c) shows that no $B 2$ LRO develops in $\mathrm{Fe}_{0.78} \mathrm{~V}_{0.22}$ at any annealing temperature, but Fig. 2(a) shows a decrease in lattice parameter with annealing time. The $\sigma$ phase does not form in $\mathrm{Fe}_{0.78} \mathrm{~V}_{0.22}$, as shown previously by x-ray diffractometry.

\section{Mössbauer spectrometry}

Mössbauer spectrometry provides information about SRO for ${ }^{57} \mathrm{Fe}$ nuclei. It is always a challenge to relate HMF's at nuclei to local chemical environments, and this local information cannot be compared directly to the LRO obtained from neutron diffractometry. In Sec. IV, hyperfine magnetic field distributions are simulated for different configurations of atom species in the nearest-neighbor shells about ${ }^{57} \mathrm{Fe}$ nuclei, and compared with experimental HFMD's to help to obtain a reasonable estimates of "Mössbauer SRO parameters." We expect the HMF at ${ }^{57} \mathrm{Fe}$ nuclei to be altered by several types of local environments in the partially ordered alloys. Antisite atoms and analogous defects associated with antiphase boundaries are expected in the ordered structure on the bcc lattice. A previous transmission electron microscopy study has identified regions of amorphous phase in ballmilled equiatomic $\mathrm{Fe}-\mathrm{V}$ alloys that contribute a paramagnetic component to the Mössbauer spectrum. ${ }^{8}$ Finally, the small
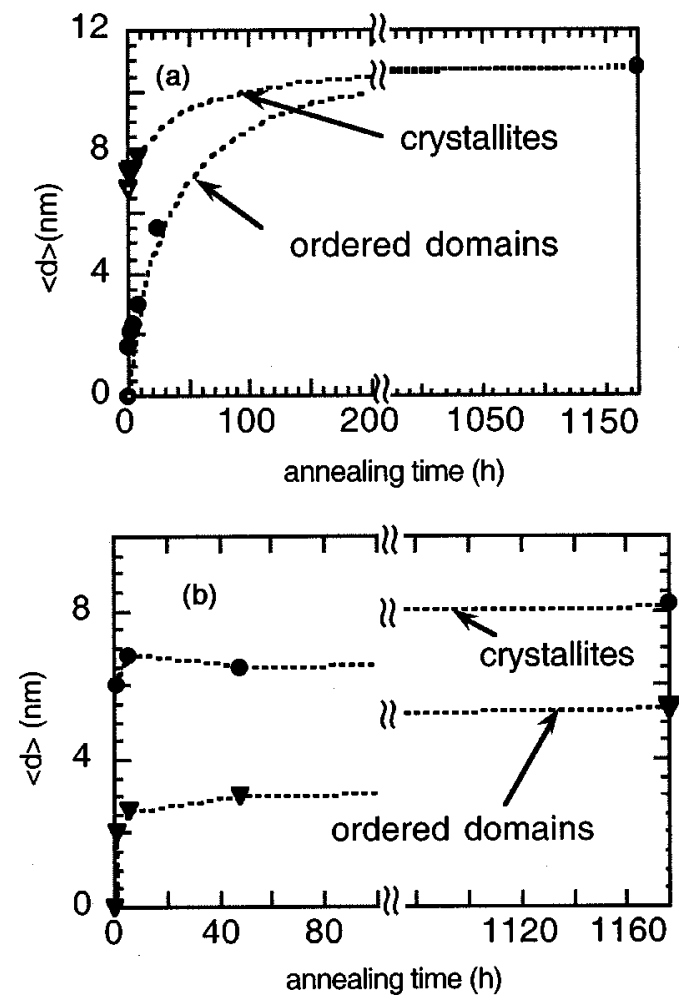

FIG. 5. Mean crystalline size (full cicles) and mean size of ordered domains (full triangles) as a function of annealing time at $723 \mathrm{~K}$ : (a) $\mathrm{Fe}_{0.53} \mathrm{~V}_{0.47}$ (b) $\mathrm{Fe}_{0.37} \mathrm{~V}_{0.63}$.

grain size allows a significant fraction of ${ }^{57} \mathrm{Fe}$ nuclei to be at and near grain boundaries, where their HMF's will differ from that of the bcc local environment.

Figures 6 and 7 present Mössbauer spectra measured at room temperature and at $8 \mathrm{~K}$, and the associated HMFD's of $\mathrm{Fe}_{0.53} \mathrm{~V}_{0.47}$ annealed for various times at $723 \mathrm{~K}$. The spectra and their HMFD's show some differences between $8 \mathrm{~K}$ and RT, but no qualitative changes. This indicates that the weak or broad components of the HMFD's at RT are indicative of specific chemical environments, and not magnetic relaxation phenomena. Clear evidence of chemical ordering is found as components of the HMFD become sharper and better defined with annealing time. The $8-\mathrm{K}$ spectrum of the as-milled alloy shows a paramagnetic contribution that is unexpected for a crystalline alloy. ${ }^{50}$ It is associated with an amorphous phase ${ }^{51}$ whose formation during milling was reported earlier. ${ }^{8}$ The amorphous phase is difficult to avoid, and is favored in the presence of oxygen-its amount was shown to increase with the oxygen content of the starting powders. ${ }^{52}$ Although the amorphous phase does occur as distinct regions, grain boundaries could also be responsible for some of this paramagnetic spectral component. The spectra of the alloy annealed for $1176 \mathrm{~h}$ are similar to those of a coarse-grained ordered alloy.

The HMFD of the as-milled sample at $8 \mathrm{~K}$ is composed of a peak at $1.6 \mathrm{~T}$ (this peak is also at $1.6 \mathrm{~T}$ at $\mathrm{RT}$ ) and of a broad peak centered around $17 \mathrm{~T}(14 \mathrm{~T}$ at $\mathrm{RT})$. During annealing, two new peaks appear rapidly at low fields $6.5 \mathrm{~T}(5$ $\mathrm{T}$ at $\mathrm{RT})$ and $11 \mathrm{~T}(8.5 \mathrm{~T}$ at RT). After annealing for $1176 \mathrm{~h}$, 

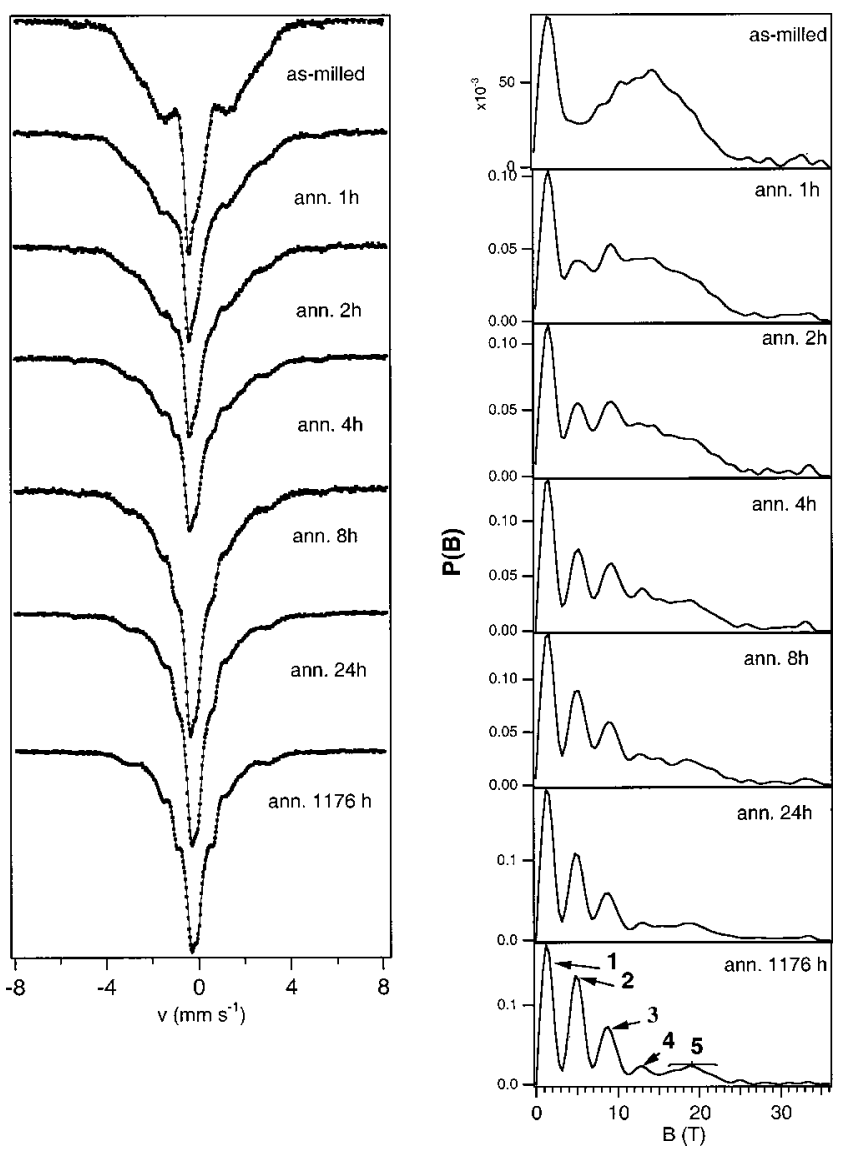

FIG. 6. ${ }^{57} \mathrm{Fe}$ Mössbauer spectra of $\mathrm{Fe}_{0.53} \mathrm{~V}_{0.47}$ at room temperature, and associated hyperfine magnetic field distributions as a function of annealing time at $723 \mathrm{~K}$.

the HMFD at $8 \mathrm{~K}$ shows distinct peaks at 1.6, 6.5, 11, and 16.4 T, denoted 1, 2, 3, and 4 in Fig. 7, and high-field components denoted 5 with a peak around $25 \mathrm{~T}$. The same distinct peaks are seen in the RT HMFD in Fig. 6 at 1.6, 5, 8.5, and $13 \mathrm{~T}$, but the high-field component 5 is broader, and centered around $19 \mathrm{~T}$.

Both the magnetic moments and the hyperfine magnetic fields in Fe-V alloys depend strongly on chemical order. ${ }^{46-50}$ As discussed in Sec. IV B, vanadium atoms are known to decrease the magnitude of the hyperfine magnetic field of iron atoms located in their two first coordination shells. $^{50,53-56}$ The low-field peaks can therefore be ascribed to $\mathrm{Fe}$ atoms surrounded by a majority of $\mathrm{V}$ atoms, the predominant local configuration for $\mathrm{Fe}$ atoms in an alloy with $B 2$ order. Component 5 of the HMFD is from $\mathrm{Fe}$ atoms with Fe-rich environments. In an alloy with significant chemical order, these environments occur for Fe atoms at antiphase boundaries or perhaps to antisite $\mathrm{Fe}$ atoms. Component 5 was assigned to antisite $\mathrm{Fe}$ atoms by Shiga and Nakamura, ${ }^{50}$ and we make the same assignment in the analysis below. During annealing at $723 \mathrm{~K}$, component 5 changes in intensity, but remains at approximately the same average HMF. The HMF of component 5 does differ for samples annealed at 723 or $773 \mathrm{~K}$ vs 823 or $873 \mathrm{~K}$. At the higher annealing temperatures, the antisite Fe atoms seem to be surrounded by more iron atoms than at the lower temperatures. The inten-
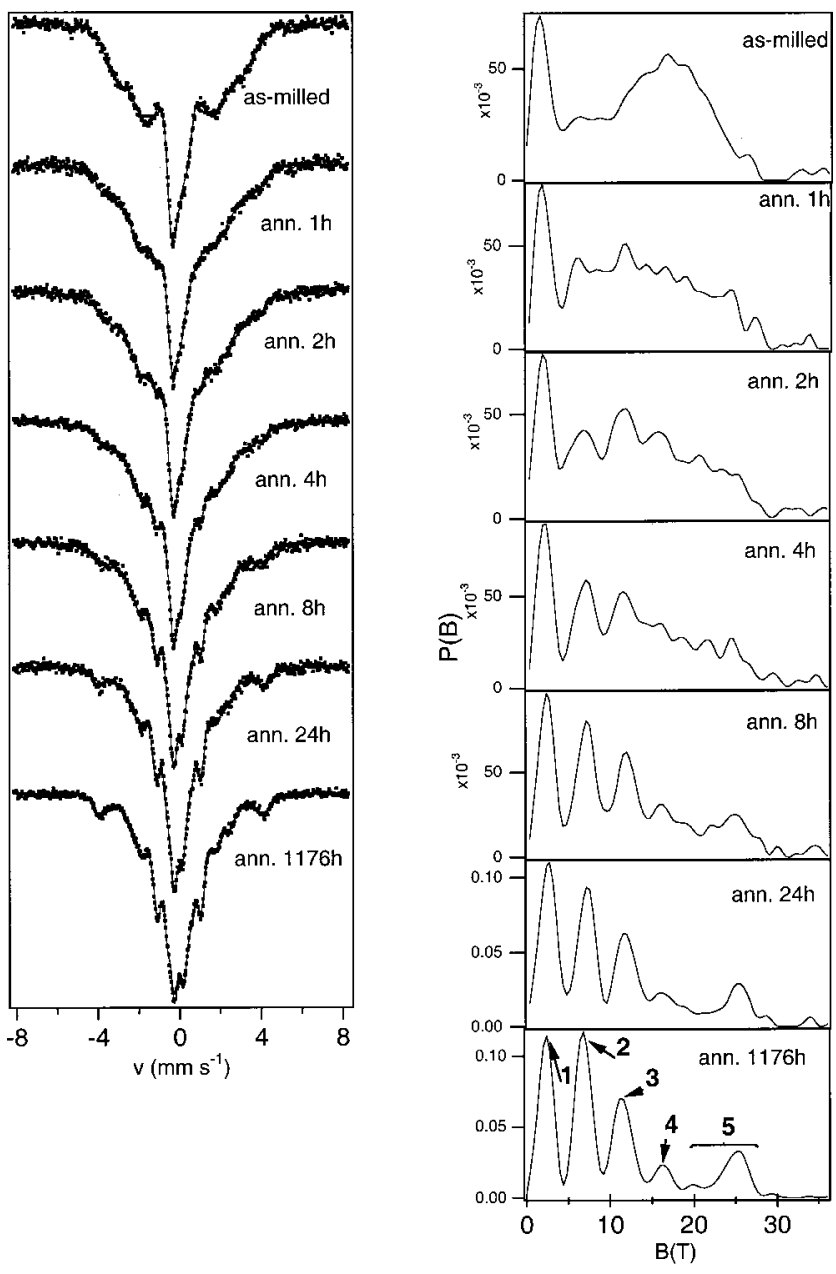

FIG. 7. ${ }^{57} \mathrm{Fe}$ Mössbauer spectra of $\mathrm{Fe}_{0.53} \mathrm{~V}_{0.47}$ at $8 \mathrm{~K}$, and associated hyperfine magnetic field distributions as a function of annealing time at $723 \mathrm{~K}$.

sities of peaks 2 and 3 increase with annealing time. The intensity of peak 1 also increases at the beginning of the annealing treatment, but then decreases slightly between 24 and $1176 \mathrm{~h}$. As discussed above, peak 1 is in part linked to iron atoms in amorphous regions or grain boundaries. Its decrease in intensity is due at least in part to grain growth and the loss of amorphous regions during thermal treatments. The HMFD's of the alloys annealed for $100 \mathrm{~h}$ at $773 \mathrm{~K}, 200$ $\mathrm{h}$ at $823 \mathrm{~K}$ and $35 \mathrm{~min}$ and $5 \mathrm{~h}$ at $873 \mathrm{~K}$ are similar to those of the alloy annealed for $1176 \mathrm{~h}$ at $723 \mathrm{~K}$. The RT Mössbauer spectra of the alloys annealed for $100 \mathrm{~h}$ at $873 \mathrm{~K}$ and for 30 min and $100 \mathrm{~h}$ at $973 \mathrm{~K}$ have only a paramagnetic contribution corresponding to the $\sigma$ phase $^{57}$ (Fig. 8).

With or without chemical order, the alloy $\mathrm{Fe}_{0.37} \mathrm{~V}_{0.63}$ is paramagnetic at room temperature. Confirmation of chemical order in $\mathrm{Fe}_{0.37} \mathrm{~V}_{0.63}$ annealed for $1176 \mathrm{~h}$ at $723 \mathrm{~K}$ is obtained by comparing the $8 \mathrm{~K}$ Mössbauer spectrum (Fig. 9) with $5 \mathrm{~K}$ Mössbauer spectra of coarse-grained ordered alloys reported in the literature. ${ }^{50} \mathrm{~A}$ minority bcc phase, if paramagnetic and $\mathrm{V}$ rich, would be impossible to detect in these Mössbauer spectra. Figure 10 shows the RT Mössbauer spectra with their HMFD's for the $\mathrm{Fe}_{0.78} \mathrm{~V}_{0.22}$ samples. During annealing at $723 \mathrm{~K}$, the HMFD narrows and shifts slightly to higher 


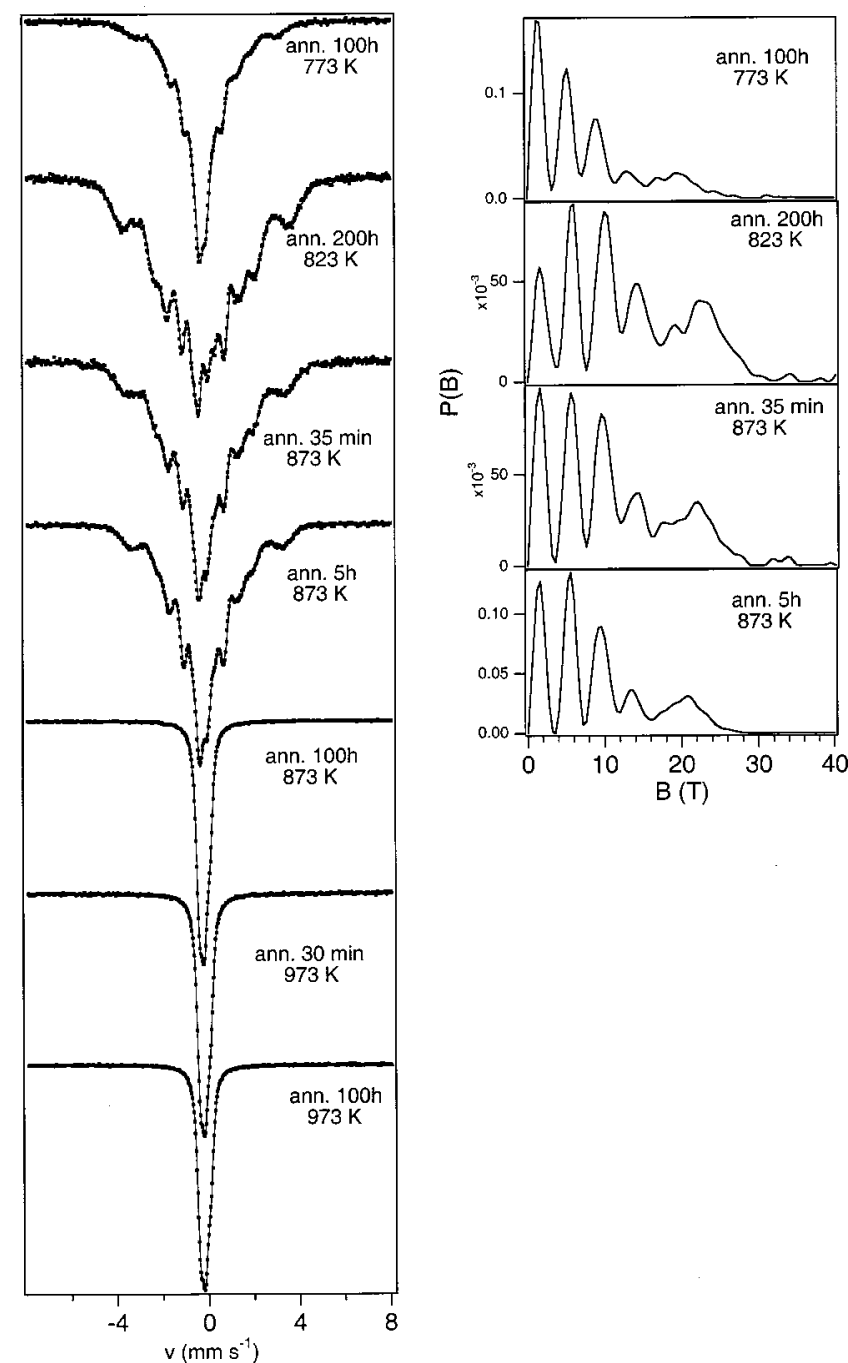

FIG. 8. ${ }^{57} \mathrm{Fe}$ Mössbauer spectra at room temperature and associated hyperfine magnetic field distributions of $\mathrm{Fe}_{0.53} \mathrm{~V}_{0.47}$ annealed at temperatures from 773 to $973 \mathrm{~K}$.

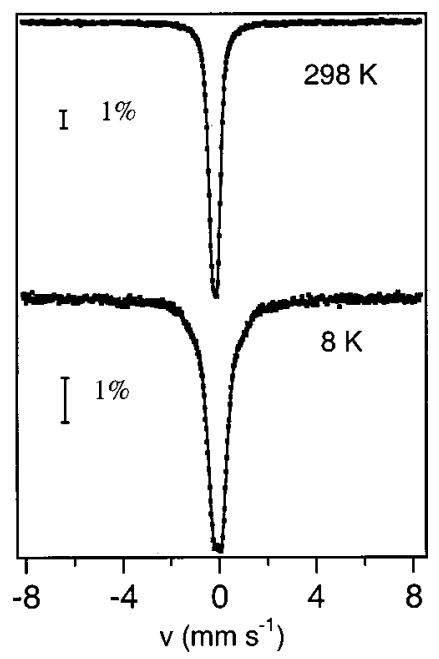

FIG. 9. ${ }^{57} \mathrm{Fe}$ Mössbauer spectra at room temperature and $8 \mathrm{~K}$ of $\mathrm{Fe}_{0.37} \mathrm{~V}_{0.63}$ annealed for $1176 \mathrm{~h}$ at $723 \mathrm{~K}$.
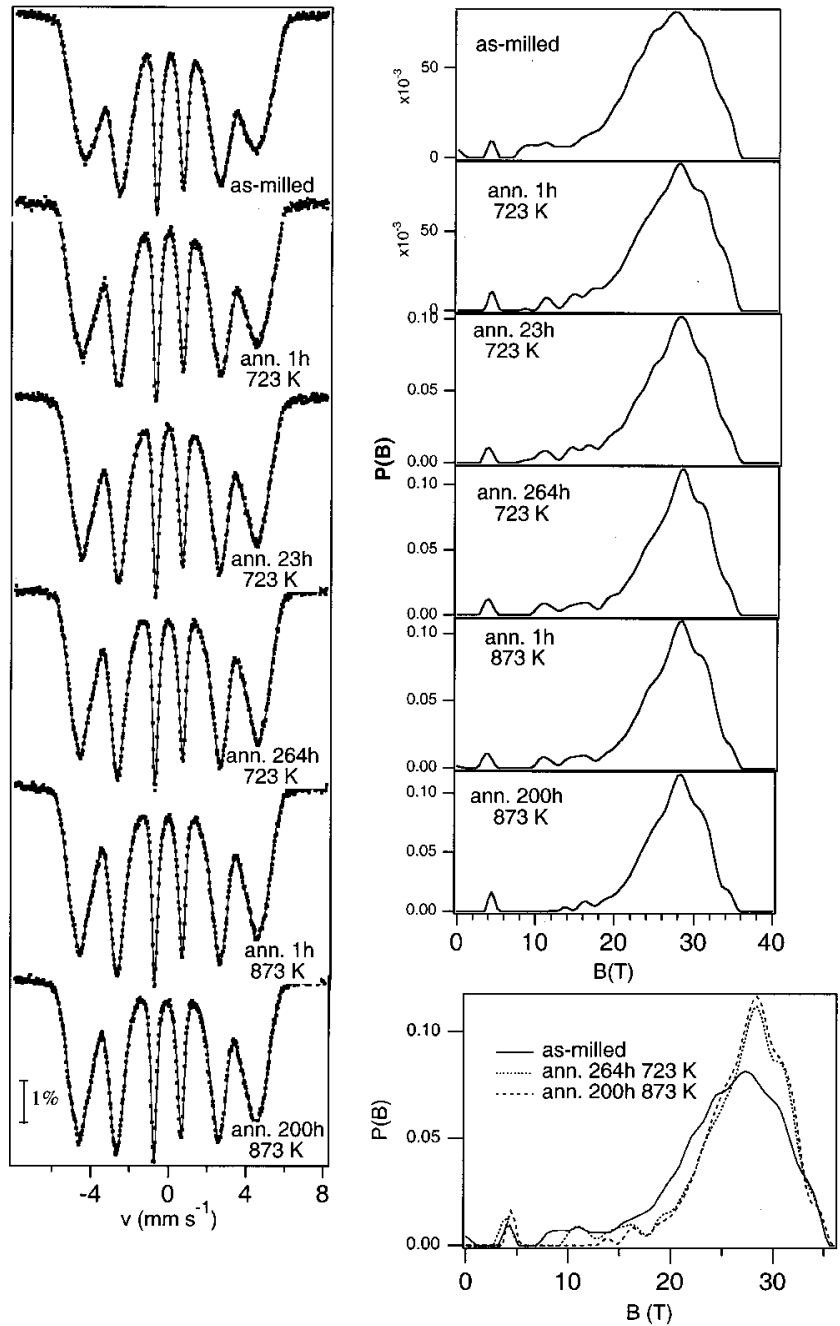

FIG. 10. ${ }^{57} \mathrm{Fe}$ Mössbauer spectra at room temperature and hyperfine magnetic field distributions of $\mathrm{Fe}_{0.78} \mathrm{~V}_{0.22}$ as-milled and annealed at temperatures from 723 to $873 \mathrm{~K}$.

fields. After a few hours of annealing, the HMFD changes more slowly, and reaches a steady state. The HMFD's of samples annealed for $264 \mathrm{~h}$ at $723 \mathrm{~K}$ and for $200 \mathrm{~h}$ at $873 \mathrm{~K}$ differ only slightly in low-amplitude components between 10 and $15 \mathrm{~T}$.

\section{SIMULATION OF HYPERFINE MAGNETIC FIELD DISTRIBUTIONS}

\section{A. The additive perturbation model for hyperfine magnetic fields}

The hyperfine magnetic field originates almost entirely from the unpaired electron spin density at the ${ }^{57} \mathrm{Fe}$ nucleus. In an alloy, the simplest case occurs when a nonmagnetic solute occupies a site in the first- or second-nearest neighbor (1nn or $2 \mathrm{nn}$ ) shell of the ${ }^{57} \mathrm{Fe}$ atom, and this solute atom does not alter the magnetic moment of the ${ }^{57} \mathrm{Fe}$ atom. The conduction electrons are changed in their spin polarization near the solute atom, and this disturbance extends to $1 \mathrm{nn}$ and $2 \mathrm{nn}$ sites about the solute. Approximately, perturbations of the 
${ }^{57} \mathrm{Fe} \mathrm{HMF}$ are added independently for each solute neighbor in its $1 \mathrm{nn}$ and $2 \mathrm{nn}$ shells, justifying the "additive perturbation model." $53-58$ This model relates the HMF at a specific ${ }^{57} \mathrm{Fe}$ atom to the specific numbers of its $1 \mathrm{nn}$ and $2 \mathrm{nn}$ vanadium atoms, $n_{\mathrm{V}}$ and $m_{\mathrm{V}}$ :

$$
B\left(n_{\mathrm{V}}, m_{\mathrm{V}}\right)=B(0,0, x)+n_{\mathrm{V}} \Delta B_{1}+m_{\mathrm{V}} \Delta B_{2},
$$

where $B(0,0, x)$ is the HMF of ${ }^{57} \mathrm{Fe}$ atoms with zero $\mathrm{V}$ neighbors in a $\mathrm{Fe}_{1-x} \mathrm{~V}_{x}$ alloy. Each first- and second-nearest neighbor $\mathrm{V}$ atom causes the ${ }^{57} \mathrm{Fe} \mathrm{HMF}$ to change by the amount $\Delta B_{1}=-3.005 \mathrm{~T}$ and $\Delta B_{2}=-2.02 \mathrm{~T}^{56}$

The assumption that magnetic moments at $\mathrm{Fe}$ atoms are unaffected by $\mathrm{V}$ neighbors becomes increasingly poor at higher $\mathrm{V}$ concentrations. The only alloy in the present study for which the additive perturbation model might work is the alloy $\mathrm{Fe}_{0.78} \mathrm{~V}_{0.22}$. For $\mathrm{Fe}_{0.78} \mathrm{~V}_{0.22}$, the mean $\langle B\rangle$ and the characteristic width $\sigma_{B}$ (where $\sigma_{B}^{2} \equiv\left\langle B^{2}\right\rangle-\langle B\rangle^{2}$ ) of the HMFD's are $\langle B\rangle=25.1,26.4,27 \mathrm{~T}$ and $\sigma_{B}=6,5.5,4.7 \mathrm{~T}$ for as-milled sample, and after annealing for $264 \mathrm{~h}$ at $723 \mathrm{~K}$ and for $200 \mathrm{~h}$ at $873 \mathrm{~K}$, respectively. It is relatively straightforward to calculate the moments of the HMFD with the model of additive perturbations, if we assume a random solid solution of bcc Fe-V. The mean HMF at room temperature given by Dubiel and $\operatorname{Zinn}^{56}$ for $x<0.18$. In units of tesla, $\langle B\rangle=32.2$ $-28.84 x$, gives $\langle B\rangle=26 \mathrm{~T}$ for $x=0.22$. In a random $\mathrm{Fe}_{1-x} \mathrm{~V}_{x}$ alloy, the second moment of the HMFD can be evaluated with Eq. (7), predicting a width of the HMFD, $\sigma_{B}=\left[x(1-x)\left(8 \Delta B_{1}^{2}+6 \Delta B_{2}^{2}\right)\right]^{1 / 2}=4.3 \mathrm{~T}$. This is in fair agreement with our experimental HFMD when we consider that the HMFD extracted from experiment is somewhat broader than the true HMFD of the sample.

We do not have a fully quantitative interpretation for the changes in the HMFD of $\mathrm{Fe}_{0.78} \mathrm{~V}_{0.22}$ upon annealing. Some of the change could be caused by grain growth, but we expect this to be a small contribution. There is little grain growth during annealing at $723 \mathrm{~K}$, especially in the first few hours when there is the largest change of the HMFD, so elimination of grain boundaries cannot account for the main differences between spectra of the as-milled and the annealed alloys. (Moreover, even though the mean grain size is $11 \mathrm{~nm}$ after $264 \mathrm{~h}$ at $723 \mathrm{~K}$ and a much larger $38 \mathrm{~nm}$ after $200 \mathrm{~h}$ at $873 \mathrm{~K}$, the HMFD's of the two alloys are similar.) We expect the changes in the HMFD of the $\mathrm{Fe}_{0.78} \mathrm{~V}_{0.22}$ after annealing are caused primarily by changes in the local chemical environments in the bcc phase. The overall change in HMFD in the range 20-35 $\mathrm{T}$ is consistent with a reduction of $\mathrm{V}$ concentration in the $1 \mathrm{nn}$ and $2 \mathrm{nn}$ shells of ${ }^{57} \mathrm{Fe}$ atoms of a few percent. The metastable phase diagram of Fig. 1 suggests that in steady state the alloy may have a majority Fe-rich bcc phase with a less than $22 \% \mathrm{~V}$ concentration, and a minority phase of B2-ordered Fe-V. The HMFD's of Fig. 10 do not show evidence for a $B 2$-ordered phase of $\mathrm{Fe}-\mathrm{V}$, which would be similar to the HMFD of the ordered phase shown in Fig. 6. Perhaps the amount of ordered phase is quite small, or perhaps the V-rich regions are very small and the interfacial Fe atoms have larger HMF's than in bulk alloys. We note that in a study of the alloy $\mathrm{Fe}_{0.30} \mathrm{Cr}_{0.70}$ prepared by ball milling, Delcroix et al. ${ }^{59}$ found a complex structure characterized by intragranular composition fluctuations of order $10 \%$ on the scale of few nanometer, attributed to a competition between alloying and demixing during milling.

\section{B. Effects of local environments on magnetic moments}

The additive perturbation model cannot be reliable for $\mathrm{Fe}_{0.53} \mathrm{~V}_{0.47}$ and $\mathrm{Fe}_{0.39} \mathrm{~V}_{0.61}$ because local variations in the vanadium concentration have large effects on the magnetic moments of iron atoms. Two effects arise to spoil the additive perturbation model. ${ }^{55,57}$ First, a change in the magnetic moment at the ${ }^{57} \mathrm{Fe}$ atom itself alters the core polarization of inner $s$ electrons and changes the HMF. Second, and more difficult to analyze, changes in the magnetic moments at the nearest-neighbor atoms around the ${ }^{57} \mathrm{Fe}$ atom cause changes in the conduction electron polarization. Strong local effects of $\mathrm{V}$ concentration on the magnetic moments of $\mathrm{Fe}$ atoms were calculated by Kakehashi ${ }^{48}$ using a local environment extension to an effective-medium model of magnetism at finite temperature. Kakehashi found that the magnetic moments at $\mathrm{Fe}$ atoms become highly sensitive to the numbers of $\mathrm{V}$ neighbors for alloys with about $50 \% \mathrm{~V}$. Nevertheless, if we had full knowledge of the numbers of nearest neighbors about each $\mathrm{Fe}$ atom, the magnetic moments on these atoms, and how the magnetic moment at the central Fe responded to this neighborhood, we could attempt to calculate the HMF distribution by a full accounting for the conduction and core electron contributions at each ${ }^{57} \mathrm{Fe}$ atom. We present an approximate analysis in what follows.

A starting point for the analysis of HMFD's is how the numbers of $1 \mathrm{nn}$ and $2 \mathrm{nn} \mathrm{V}$ atoms around the ${ }^{57} \mathrm{Fe}$ atoms depend on the state of order in the alloy. Any relationship between one LRO parameter and the nearest-neighbor chemical environments is necessarily an approximation in the sense that an LRO parameter cannot define unique SRO parameters in partially ordered alloys. Consistent with a point approximation, we assumed that the $1 \mathrm{nn}$ and $2 \mathrm{nn}$ shells had Fe and $\mathrm{V}$ concentrations that depended only on sublattice occupancies (i.e., mean-field SRO correlations were assumed). For an alloy of composition $\mathrm{Fe}_{0.5-\Delta x} \mathrm{~V}_{0.5+\Delta x}$, the probability for an iron atom to have $n_{\mathrm{Fe}}$ and $m_{\mathrm{Fe}}$ iron atoms as first-nearest and second-nearest neighbors is

$$
\begin{aligned}
P\left\{\mathrm{Fe}, n_{\mathrm{Fe}}, m_{\mathrm{Fe}}\right\}= & \frac{[\mathrm{Fe}]_{\mathrm{Fe}}}{1-2 \Delta x} P\left\{[\mathrm{Fe}]_{\mathrm{Fe}}, n_{\mathrm{Fe}}, m_{\mathrm{Fe}}\right\} \\
& +\frac{[\mathrm{Fe}]_{\mathrm{V}}}{1-2 \Delta x} P\left\{[\mathrm{Fe}]_{\mathrm{V}}, n_{\mathrm{Fe}}, m_{\mathrm{Fe}}\right\},
\end{aligned}
$$

where $P\left\{[\mathrm{Fe}]_{Y}, n_{\mathrm{Fe}}, m_{\mathrm{Fe}}\right\}=P_{1}\left\{[\mathrm{Fe}]_{Y}, n_{\mathrm{Fe}}\right\} \times P_{2}\left\{[\mathrm{Fe}]_{Y}, m_{\mathrm{Fe}}\right\}$. The notation is $Y=\mathrm{Fe}$ or $\mathrm{V}$, and $[\mathrm{Fe}]_{\mathrm{Fe}},[\mathrm{Fe}]_{\mathrm{V}}$ are the iron concentrations on the Fe and $\mathrm{V}$ sublattices. The probabilities for an iron atom on the $Y$ sublattice to have $n_{\mathrm{Fe}}$ iron atoms as first-nearest neighbors, or $m_{\mathrm{Fe}}$ iron atoms as second-nearest neighbors are

$$
P_{1}\left\{[\mathrm{Fe}]_{Y}, n_{\mathrm{Fe}}\right\}=\left(\begin{array}{c}
8 \\
n_{\mathrm{Fe}}
\end{array}\right)\left([\mathrm{Fe}]_{Z}\right)^{n_{\mathrm{Fe}}}\left(1-[\mathrm{Fe}]_{Z}\right)^{8-n_{\mathrm{Fe}}},
$$

and 


$$
P_{2}\left\{[\mathrm{Fe}]_{Y}, m_{\mathrm{Fe}}\right\}=\left(\begin{array}{c}
6 \\
m_{\mathrm{Fe}}
\end{array}\right)\left([\mathrm{Fe}]_{Y}\right)^{m_{\mathrm{Fe}}}\left(1-[\mathrm{Fe}]_{Y}\right)^{6-m_{\mathrm{Fe}}},
$$

respectively. Since first neighbors are on the opposite sublattice in the $B 2$ structure, here $Z=\mathrm{V}$ when $Y=\mathrm{Fe}$, and $Z$ $=\mathrm{Fe}$ when $Y=\mathrm{V}$. The atoms of the second neighbor shell belong to the same sublattice, however, so only subscripts $Y$ appear in Eq. (10).

With information on the numbers of nearest neighbors, the next step is to calculate the HMF of an iron atom in the $\left[\mathrm{Fe}, n_{\mathrm{Fe}}, m_{\mathrm{Fe}}\right]$ configuration. We used a model proposed by Shiga and Nakamura for V-rich bcc alloys. ${ }^{50}$ Their model first relates the magnetic moment $\left(\right.$ in $\mu_{B}$ ) of an iron atom to the number of iron atoms in its $1 \mathrm{nn}$ shell:

$$
\mu_{\mathrm{Fe}}\left(n_{\mathrm{Fe}}\right)=\left\{\begin{array}{l}
0.233 n_{\mathrm{Fe}} \quad\left(n_{\mathrm{Fe}} \leqslant 2\right) \\
0.384+0.2597 n_{\mathrm{Fe}} \quad\left(n_{\mathrm{Fe}} \geqslant 3\right) .
\end{array}\right.
$$

The magnetic hyperfine field (in tesla) is then calculated from a semiempirical relation: ${ }^{50}$

$$
B\left(n_{\mathrm{Fe}}, m_{\mathrm{Fe}}\right)=7 \mu_{\mathrm{Fe}}\left(n_{\mathrm{Fe}}\right)+0.63 n_{\mathrm{Fe}}\left\langle\mu_{\mathrm{Fe}}\right\rangle+0.53 m_{\mathrm{Fe}}\left\langle\mu_{\mathrm{Fe}}\right\rangle,
$$

with

$$
\begin{aligned}
\left\langle\mu_{\mathrm{Fe}}\right\rangle= & \sum_{n_{\mathrm{Fe}}} \frac{\mu_{\mathrm{Fe}}\left(n_{\mathrm{Fe}}\right)}{(1-2 \Delta x)}\left([\mathrm{Fe}]_{\mathrm{Fe}} P_{1}\left\{[\mathrm{Fe}]_{\mathrm{Fe}}, n_{\mathrm{Fe}}\right\}\right. \\
& \left.+[\mathrm{Fe}]_{\mathrm{V}} P_{1}\left\{[\mathrm{Fe}]_{\mathrm{V}}, n_{\mathrm{Fe}}\right\}\right) .
\end{aligned}
$$

The actual HMFD's are then simulated by summing Gaussian peaks centered on the different values of $B\left(n_{\mathrm{Fe}}, m_{\mathrm{Fe}}\right)$, with weights proportional to $P\left(\mathrm{Fe}, n_{\mathrm{Fe}}, m_{\mathrm{Fe}}\right)$ of Eq. (8). To approximate experimental resolution, the standard deviations of all Gaussians were $1.0 \mathrm{~T}$.

\section{HMF's of local environments}

The approximations of chemical environments and their relationship to the HMF were adequate for the identification of the various peaks in the HMFD's of Figs. 6 and 7, and to provide approximate relationships between components in the HMFD and the LRO in the alloy. Figure 11 presents HMFD's calculated for the $\mathrm{Fe}_{0.53} \mathrm{~V}_{0.47}$ alloy with various LRO parameters $S$. The features of Figs. 6 and 7 are reproduced, and the origins of the five peaks were identified with Eq. (12). Peaks 1 and 2 originate with Fe atoms having eight $\mathrm{V} 1 \mathrm{nn}$ atoms and 0 or $1 \mathrm{Fe} 2 \mathrm{nn}$ atoms, i.e., $[\mathrm{Fe}, 8,0]$ and $[\mathrm{Fe}, 8,1]$. Peaks 3 and 4 are more ambiguous - they originate with different atom complements in $1 \mathrm{nn}$ and $2 \mathrm{nn}$ shells. The broad peak 5 is identified as antisite iron atoms, i.e., Fe atoms on the V sublattice with a Fe-rich $1 \mathrm{nn}$ shell.

For disordered $\mathrm{Fe}_{0.53} \mathrm{~V}_{0.47}$, the overall shape of the HMFD in Fig. $11(S=0)$ is in good agreement with experiment, although the HMFD from the as-milled sample includes a low-field peak from amorphous phase and grain boundaries. The maximum in the simulated HMFD was $16.2 \mathrm{~T}$ for $S$ $=0$, which compares well to the maximum of the experimental HFMD of coarse-grained bcc $\mathrm{Fe}_{0.50} \mathrm{~V}_{0.50}$ at $5 \mathrm{~K}$ (Ref. 50)

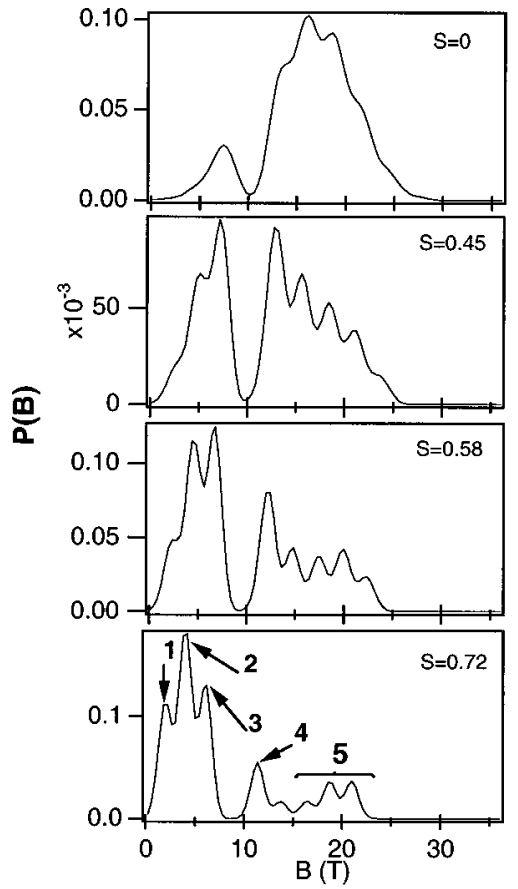

FIG. 11. HMFD's of $\mathrm{Fe}_{0.53} \mathrm{~V}_{0.47}$ simulated at $5 \mathrm{~K}$ with the model of Shiga and Nakamura ${ }^{50}$ for different values of the LRO parameter $S$.

at $16.5 \pm 0.7 \mathrm{~T}$, and $16.8 \pm 0.4 \mathrm{~T}$ for our as-milled $\mathrm{Fe}_{0.53} \mathrm{~V}_{0.47}$ at $8 \mathrm{~K}$ (Fig. 9). The experimental HMFD also has a little more intensity in the range 4-10 $\mathrm{T}$.

The mean HMF was calculated as a function of LRO parameter by using the Shiga-Nakamura model with moment data for $5 \mathrm{~K}$. This $\langle B\rangle(S)$ decreases with LRO parameter as $\langle B\rangle(S)=16.7-4.1 S-11.6 S^{2}$ (in tesla). Deleting the contribution of peak 1 from the HMFD of the as-milled sample, the experimental $\langle B\rangle$ is $15.8 \pm 0.8 \mathrm{~T}$. This corresponds to an LRO parameter $S=0.15 \pm 0.10$, indicating that the as-milled sample is essentially disordered within the limits of Mössbauer spectrometry data. Beyond our assumption of a random alloy, some of the contribution to peak 1 may originate with $\mathrm{Fe}$ atoms in V-rich environments caused by local fluctuations in the chemical order. Such LRO heterogeneities were reported, for example, in as-milled $B 2 \mathrm{Fe}_{60} \mathrm{Al}_{40} \cdot{ }^{19}$

We used the intensity of peak 2, normalized to the distribution after removal of peak 1 , to determine a Mössbauer order parameter from the experimental intensities. Figure 12(a) shows the simulated relationship between $S$ and this intensity of peak 2 . This relationship was used to convert the intensity of peak 2 into a "Mössbauer order parameter" $S_{M}$. Figure 12(b) shows that for the alloy $\mathrm{Fe}_{0.53} \mathrm{~V}_{0.47}$, similar annealing responses were found for $S$ (from neutron diffraction) and $S_{M}$. A somewhat faster evolution of $S_{M}$ than $S$ may occur in the first few hours, perhaps because Mössbauer spectrometry is more sensitive to short-range order. Both order parameters reach a steady state at approximately 0.7 .

Finally, a simulation of the HMFD of ordered $\mathrm{Fe}_{0.37} \mathrm{~V}_{0.63}$ was consistent with the experimental HMFD at $8 \mathrm{~K}$ from material annealed for $1176 \mathrm{~h}$ at $723 \mathrm{~K}$ (Fig. 9). Unfortunately, the experimental HMFD does not have sufficient 

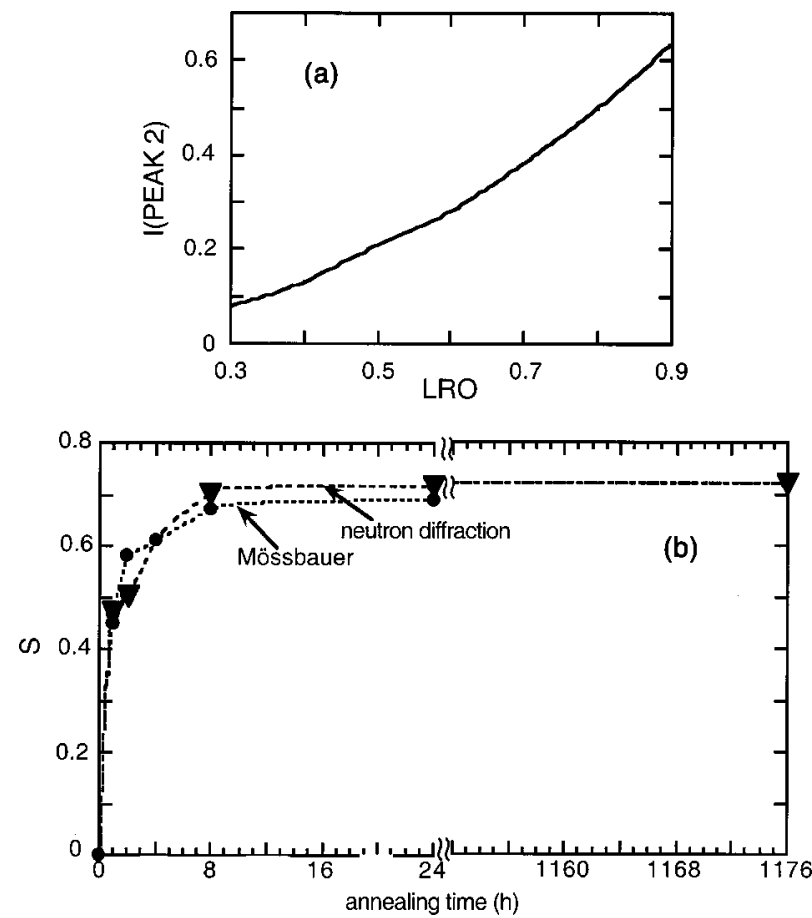

FIG. 12. (a) Calculated intensity of peak 2 of the HMFD's as a function of the LRO parameter. (b) LRO parameter obtained from HMFD's (full circles) and from neutron diffraction patterns (full triangles) as a function of annealing time at $723 \mathrm{~K}$.

resolution to provide reliable order parameters or show the coexistence of $A 2$ and $B 2$ phases.

\section{DISCUSSION}

\section{A. Pair interactions and metastable equilibrium}

The phase diagrams in Fig. 1 were calculated by Sanchez et al., ${ }^{4}$ from pairwise interactions deduced from experimental SRO parameters measured at $1133 \mathrm{~K}$ (thin line) and 1473 $\mathrm{K}$ (thick line), respectively, by Pierron-Bohnes et al., ${ }^{5}$ on a single crystal of $\mathrm{Fe}_{0.804} \mathrm{~V}_{0.196}$. We also extracted pair interactions from the same set of SRO parameters at $1133 \mathrm{~K}$ using a variant of the cluster variation method (CVM) described by Pierron-Bohnes et al. ${ }^{5}$ Although our intent was to assess the temperature dependence of the LRO parameter, we obtained information on the phase boundaries of Fig. 1. The CVM approximation used here includes a body-centered cube and an octahedron. Using the inverse method of Gratias and

TABLE IV. Effective pair interactions calculated from SRO parameters of $\mathrm{Fe}_{0.804} \mathrm{~V}_{0.196}$ at $1133 \mathrm{~K}^{.44} J_{n}$ (present work) and $V_{n}$ (Refs. 4 and 5)

\begin{tabular}{ccc}
\hline \hline$n$ & $J_{n}(\mathrm{meV})$ & $V_{n}(\mathrm{meV})$ \\
\hline 1 & 9.5 & 9.8 \\
2 & -1.5 & -1.2 \\
3 & -2 & -4.6 \\
4 & & -1.2 \\
5 & -0.3 & -1.9 \\
\hline \hline
\end{tabular}

TABLE V. Calculated LRO parameters (BW is Bragg-Williams, CVM is cluster variation method) and experimental LRO parameters at $\left(T / T_{c}\right)$ for $\mathrm{Fe}_{0.53} \mathrm{~V}_{0.47}\left(T_{c}=1138 \mathrm{~K}, S_{m}=0.94\right)$.

\begin{tabular}{ccccc}
\hline \hline$T(\mathrm{~K})$ & $T / T_{c}$ & $S_{\mathrm{BW}}\left(T / T_{c}\right)$ & $S_{\mathrm{CVM}}\left(T / T_{c}\right)$ & $S_{\text {expt. }}\left(T / T_{c}\right)$ \\
\hline 723 & 0.63 & 0.86 & 0.90 & 0.72 \\
773 & 0.68 & 0.83 & 0.87 & 0.76 \\
823 & 0.72 & 0.79 & 0.84 & 0.62 \\
873 & 0.77 & 0.74 & 0.80 & 0.75 \\
\hline \hline
\end{tabular}

Cénédèse, ${ }^{60}$ this cluster permits determination of the first three and the fifth effective pair interactions, which are presented in Table IV along with those published previously. ${ }^{4,5}$ We obtained critical temperatures of 1130 and $1052 \mathrm{~K}$ for $\mathrm{Fe}_{0.50} \mathrm{~V}_{0.50}$ and $\mathrm{Fe}_{0.38} \mathrm{~V}_{0.62}$, respectively, which correspond well with the values of $1140 \pm 15$ and $1070 \pm 15 \mathrm{~K}$ obtained from the experiments of Seki, Hagiwara, and Suzuki. ${ }^{2}$ Our metastable phase diagram is essentially the same as that shown in Fig. 1. ${ }^{4}$ Our experimental results are shown as points on Fig. 1. The experimental points seem mostly consistent with the diagram drawn with thick lines, possibly with a slight asymmetry with respect to the equiatomic composition. Alternatively, they could agree with the diagram drawn with thin lines if it were given a greater asymmetry in composition. Our results are most reliable for the lower temperatures, where enhanced kinetics in nanocrystalline materials allow steady state to be reached in reasonable times. The high density of grain boundaries in nanocrystals promotes the formation of $\sigma$ phase at higher temperatures.

Using our CVM effective pair interactions, we calculated the equilibrium LRO parameter of $\mathrm{Fe}_{0.53} \mathrm{~V}_{0.47}$ as a function of temperature. Table V and Fig. 13 compare the steady-state experimental values of the LRO parameter $S$ as a function of $T / T_{c}$, along with LRO from CVM calculations, and from the classical Bragg-Williams model where

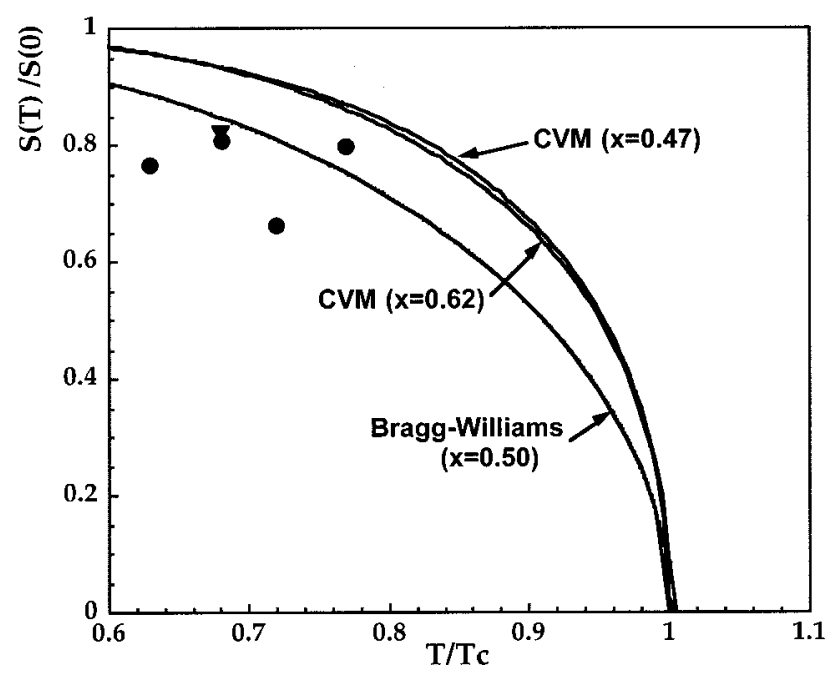

FIG. 13. Reduced LRO parameter $S / S_{m}$ of $\mathrm{Fe}_{1-x} \mathrm{~V}_{x}$ as a function of $T / T_{c}$ calculated with the CVM model and Bragg-Williams model. Full circles are for $x=0.47$ and full triangle is for $x=0.39$ for the longest annealing times. 


$$
\frac{T}{T_{c}}=\frac{2 S_{\mathrm{BW}}}{\left(1-4 \Delta x^{2}\right)\left[\tanh ^{-1}\left(\frac{S_{\mathrm{BW}}}{1-2 \Delta x}\right)+\tanh ^{-1}\left(\frac{S_{\mathrm{BW}}}{1+2 \Delta x}\right)\right]}
$$

for $T / T_{c}<1$. The experimental LRO parameters are smaller than the values expected for equilibrium. Moreover, $S$ does not decrease with annealing temperature.

\section{B. Defect structures and ordering kinetics}

The combination of Mössbauer spectrometry data on antisite atoms and order parameters, and quantitative data on LRO parameters from neutron diffractometry measurements, enables us to assess the presence of different local structures in the transient states of order. One might expect that the kinetics and mechanisms of chemical ordering could be altered by the nanocrystalline nature of the material. Any material with a $\sim 7 \mathrm{~nm}$ grain size has a high density of grain boundaries. Approximately $10 \%$ of the atoms in the crystals are at the edges of the crystals, adjacent to grain boundaries. It is possible that these atoms are less well distributed on their appropriate sublattices, suppressing the LRO. An even higher density of antiphase boundaries exists in these materials, since the domain sizes are only $2-3 \mathrm{~nm}$ in the early stages of ordering. Some chemical disorder is possible around antiphase domain boundaries. Monte Carlo simulations of ordering with a vacancy mechanism at low temperatures have revealed a high density of antisite defects once ordered domain formation is complete. ${ }^{31-33}$ The high antisite population is quite different from the clean ordered domains during ordering by interchanges of atom pairs, for example, even when the domain structures are comparable. ${ }^{31}$ Antiphase domain boundaries serve as traps for vacancies, ${ }^{32}$ reducing their effectiveness in annealing out the antisite atoms, and the motion of the APB's is not always conservative. This transient population of antisite atoms is responsible for a slow coarsening regime at low temperature. ${ }^{33}$ Once the APB's are eliminated, the last antisite atoms are removed slowly. ${ }^{31,33}$

Figure 13 shows that the equilibrium state of order in $\mathrm{Fe}_{0.53} \mathrm{~V}_{0.47}$ is lower than expected at all temperatures. The experimental points were taken long times after the crystallites were single domains. Disorder near APB's is not the source of this discrepancy. It is tempting to attribute the low equilibrium order in $\mathrm{Fe}-\mathrm{V}$ to disorder at the peripheries of crystallites near the grain boundaries, but this simple hypothesis is ruled out by several observations. First, the LRO parameters were not sensitive to grain growth. Figure 14 shows little change in $S$ (about 0.7) when most grain growth occurred. Second, nearly all the change in $S$ is accounted for by the change in population of antisite defects.

The fraction of ${ }^{57} \mathrm{Fe}$ atoms surrounded by $\mathrm{Fe}$ atoms, which are antisite ${ }^{57} \mathrm{Fe}$ atoms when $S$ is large enough to allow for a distinct $\mathrm{V}$ sublattice, is obtained from contribution 5 in the HMFD (Figs. 8 and 11). The fraction $f_{5}$ given in Table VI was calculated from the relative area of roomtemperature HMFD's in the range $16 \leqslant B \leqslant 30 \mathrm{~T}$, after removal of peak 1 and normalizing to the remaining HMFD.

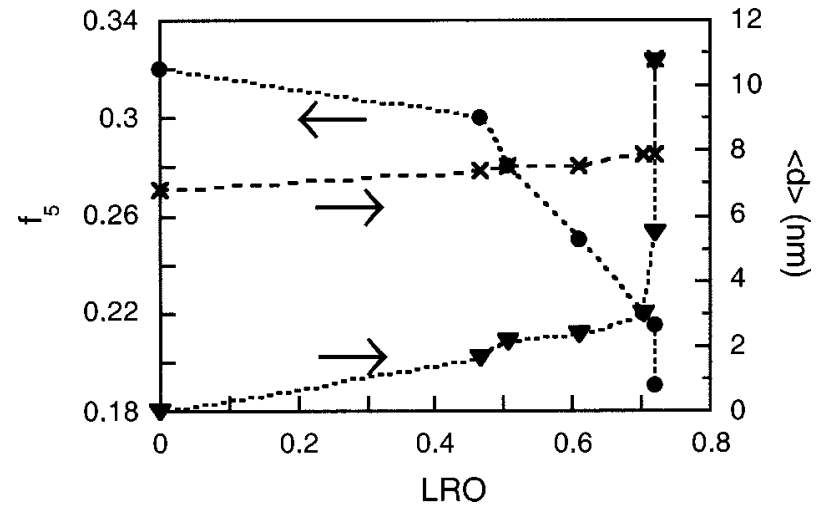

FIG. 14. Size of ordered domains and of crystallites (full triangles, crosses, right scale) and $f_{5}$ (full circles, left scale) as a function of the LRO parameter for $\mathrm{Fe}_{0.53} \mathrm{~V}_{0.47}$ annealed at $723 \mathrm{~K}$ (except for $S=0$ which corresponds to the as-milled state).

These experimental fractions $f_{5}$ for $\mathrm{Fe}_{0.53} \mathrm{~V}_{0.47}$ were in excellent agreement with simulated fractions of antisite defects, obtained by assuming that all the chemical disorder was caused by antisite atoms. Using the measured $S$ and distributing antisite atoms at random, $f_{5}$ was $0.31,0.28,0.22$, and 0.19 for samples annealed respectively for $1,2,4$ and $8 \mathrm{~h}$ at $723 \mathrm{~K}$ (Table VI). A much higher value 0.56 is calculated for $S=0$, partly because the definition of class 5 is ambiguous when the alloy is strongly disordered, as seen from the HFMD's in Figs. 6 and 7.

Figure 14 shows the evolution of the size of ordered domains as a function of the LRO parameter for $\mathrm{Fe}_{0.53} \mathrm{~V}_{0.47}$ annealed at $723 \mathrm{~K}$. The size of ordered domains increases linearly with the LRO parameter $(\langle d\rangle \approx 4 S)$ up to $S \approx 0.7$, a value close to the steady-state value. This implies the density of APB's decreases inversely with the LRO parameter. Consistent with our observation that the disorder in the alloy is dominated by antisite defects, Fig. 14 shows that the fraction of antisite Fe atoms, $f_{5}$, decreases with LRO. This observation is qualitatively consistent with the Monte Carlo results that the presence of APB's may be responsible for a transient

TABLE VI. Relative intensity and mean hyperfine magnetic field of component 5 of the room-temperature HMFD's of $\mathrm{Fe}_{0.53} \mathrm{~V}_{0.47}$ in the as-milled state and as a function of annealing time at various temperatures.

\begin{tabular}{ccc}
\hline \hline Annealing treatment & $f_{5} \pm 0.02$ & $\langle B\rangle_{5}(\mathrm{~T}) \pm 0.4 \mathrm{~T}$ \\
\hline As-milled & 0.32 & 19.4 \\
$1 \mathrm{~h}$ at $723 \mathrm{~K}$ & 0.30 & 19.9 \\
$2 \mathrm{~h}$ at $723 \mathrm{~K}$ & 0.28 & 20.0 \\
$4 \mathrm{~h}$ at $723 \mathrm{~K}$ & 0.25 & 19.9 \\
$8 \mathrm{~h}$ at $723 \mathrm{~K}$ & 0.22 & 20.1 \\
$24 \mathrm{~h}$ at $723 \mathrm{~K}$ & 0.22 & 20.1 \\
$1176 \mathrm{~h}$ at $723 \mathrm{~K}$ & 0.19 & 19.6 \\
$100 \mathrm{~h}$ at $773 \mathrm{~K}$ & 0.22 & 19.9 \\
$200 \mathrm{~h}$ at $823 \mathrm{~K}$ & 0.37 & 21.9 \\
35 min at $873 \mathrm{~K}$ & 0.31 & 21.1 \\
$5 \mathrm{~h}$ at $873 \mathrm{~K}$ & 0.24 & 20.4 \\
\hline \hline
\end{tabular}


TABLE VII. Calculated and experimental LRO parameters at $\left(T / T_{c}\right)$ for $\mathrm{Fe}_{0.37} \mathrm{~V}_{0.63}\left(T_{c}=1063 \mathrm{~K}, S_{m}=0.74\right)$ and for $\mathrm{Fe}_{0.39} \mathrm{~V}_{0.61}$ $\left(T_{c}=1083 \mathrm{~K}, S_{m}=0.78\right)$.

\begin{tabular}{ccccc}
\hline \hline$T(\mathrm{~K})$ & $T / T_{c}$ & $S_{\mathrm{BW}}\left(T / T_{c}\right)$ & $S_{\mathrm{CVM}}\left(T / T_{c}\right)$ & $S_{\text {expt. }}\left(T / T_{c}\right)$ \\
\hline $723^{\mathrm{a}}$ & 0.68 & 0.67 & 0.71 & 0.61 \\
773 & 0.71 & 0.69 & 0.69 & 0.52 \\
873 & 0.80 & 0.61 & 0.61 & 0.67 \\
973 & 0.89 & 0.47 & 0.46 & 0.67 \\
\hline \hline
\end{tabular}

${ }^{\mathrm{a}} \mathrm{Fe}_{0.37} \mathrm{~V}_{0.63}$

population of antisite atoms. ${ }^{31,33}$ Figure 14 also shows a reduction in $f_{5}$ at late times when the crystals are single domains without APB's. The steady-state LRO parameter is smaller than the equilibrium value because of residual antisite defects that do not anneal out on the time scale of the experiments. The elimination of antisite defects requires some longer-range diffusion, which is very slow in ordered domains at low temperatures. The kinetics at the later stages of annealing may also be suppressed by a low vacancy concentration. At the higher temperature of $873 \mathrm{~K}$, however, once the domain size grows to the crystal size, $S$ then increases from 0.64 to 0.75 (Table III), which is close to the value expected in thermodynamic metastable equilibrium (Table V).

The nature of the disorder-order transition, first or second order, is difficult to establish because both may lead to similar microstructures in the early stages with small ordered domains. Our measurements at $723 \mathrm{~K}$ suggest that the transformation is first order. The difference in lattice parameters from fundamental and superlattice diffractions, $a_{f}-a_{s}$, suggests that two phases coexist for short annealing times, but $a_{s}$ was obtained from broad and weak diffractions. Highresolution transmission electron microscopy and/or smallangle neutron scattering would perhaps provide more definitive evidence for the nature of the phase transition.

As discussed in Sec. III B 3, the $\mathrm{Fe}_{0.37} \mathrm{~V}_{0.63}$ alloy annealed at $723 \mathrm{~K}$ is a mixture of two phases, an ordered one and a disordered one. The LRO parameter measured at $723 \mathrm{~K}$ is thus an average that cannot be compared to the LRO parameter of a single-phase alloy. At $773 \mathrm{~K}$ the $\mathrm{Fe}_{0.39} \mathrm{~V}_{0.61}$ alloy is single-phase and its LRO parameter is smaller than the equilibrium value calculated with the CVM (Table VII). This can also be accounted for by antisite defects as for $\mathrm{Fe}_{0.53} \mathrm{~V}_{0.47}$. At temperatures close to $T_{c}$, the LRO parameters of $\mathrm{Fe}_{0.39} \mathrm{~V}_{0.61}$ are larger than the calculated ones (Table VII), but the measured LRO parameters are uncertain owing to the fast formation of $\sigma$ phase at these temperatures.

\section{CONCLUSIONS}

The $B 2$ ordering of disordered bcc Fe-V alloys was studied by $\mathrm{x}$-ray and neutron diffractometries and by Mössbauer spectrometry for four alloys, $\mathrm{Fe}_{0.78} \mathrm{~V}_{0.22}, \mathrm{Fe}_{0.53} \mathrm{~V}_{0.47}$, $\mathrm{Fe}_{0.39} \mathrm{~V}_{0.61}$, and $\mathrm{Fe}_{0.37} \mathrm{~V}_{0.63}$, at temperatures from 723 to 973 $\mathrm{K}$. The disordered materials, prepared by ball milling, had nanocrystalline microstructures. A method was developed for analyzing Mössbauer spectra in concentrated ferromagnetic $\mathrm{Fe}-\mathrm{V}$ alloys when magnetic moments depend strongly on local environments, and the method provided LRO parameters in good agreement with those measured by neutron diffractometry. The Mössbauer hyperfine magnetic field distributions then proved useful for quantifying the number of antisite $\mathrm{Fe}$ atoms in partially ordered alloys.

As observed for other ordered nanocrystalline alloys, $\mathrm{Fe}_{0.53} \mathrm{~V}_{0.47}$ and $\mathrm{Fe}_{0.39} \mathrm{~V}_{0.61}$ order rapidly at moderate temperatures. Their steady-state LRO parameters at $723 \mathrm{~K}$ were smaller than expected for thermodynamic metastable equilibrium, as calculated here by the cluster variation method. The steady-state LRO parameter did not decrease as expected with increasing temperature. These results are consistent with a large population of antisite defects detected by Mössbauer spectrometry. These antisite defects seem to be associated with the presence of antiphase domain boundaries and their motion during domain coarsening. The elimination of antisite defects occurs at a later stage of the ordering process once the crystals are single ordered domains.

Our measured steady-state LRO parameters are generally consistent with the metastable $\mathrm{Fe}-\mathrm{V}$ phase diagram calculated by Sanchez et al. ${ }^{4}$ In particular, their phase diagram predicts that the metastable equilibrium state of a $\mathrm{Fe}_{0.37} \mathrm{~V}_{0.63}$ alloy at $723 \mathrm{~K}$ is a two-phase mixture, in agreement with our neutron diffraction results.

\section{ACKNOWLEDGMENTS}

We thank Pierre Delcroix (LSG2M) and Bernard Malaman (Université Henri-Poincaré, Nancy) for their help with the measuring of Mössbauer spectra. We are indebted to the Institut Laue-Langevin (ILL, Grenoble) and to CNRS for the use of the DlB instrument operating as a Collaborative Research Group. B.F. acknowledges NSF Grant No. DMR9816617.
*Present address: Groupe Matière Condensée et Matériaux, U.M.R. C.N.R.S. 6626, Université de Rennes-I, Avenue du Général Leclerc, F-35042 Rennes Cedex, France (email address: gerard.lecaer@univ-rennes1.fr).

${ }^{1}$ Binary Alloy Phase Diagrams, edited by T. B. Massalski (American Society for Metals, Metals Park, Ohio, 1986), Vol. 2, p. 1122 .

${ }^{2}$ J. I. Seki, M. Hagiwara, and T. Suzuki, J. Mater. Sci. 14, 2404 (1979).

${ }^{3}$ R. J. Chandross and D. P. Shoemaker, J. Phys. Soc. Jpn. 17, 16 (1962).
${ }^{4}$ J. M. Sanchez, M. C. Cadeville, V. Pierron-Bohnes, and G. Inden, Phys. Rev. B 54, 8958 (1996).

${ }^{5}$ V. Pierron-Bohnes, E. Kentzinger, M. C. Cadeville, J. M. Sanchez, R. Caudron, F. Solal, and R. Kozubski, Phys. Rev. B 51, 5760 (1995).

${ }^{6}$ H. Bakker, G. F. Zhou, and H. Yang, Prog. Mater. Sci. 39, 159 (1995).

${ }^{7}$ C. Suryanarayana, Prog. Mater. Sci. 46, 1 (2001).

${ }^{8}$ B. Fultz, G. Le Caër, and P. Matteazzi, J. Mater. Res. 4, 1450 (1989).

${ }^{9}$ T. Koyano, K. Chatani, T. Fukunaga, and U. Mizutani, Mater. Sci. 
Eng., A 181-182, 1277 (1994).

${ }^{10}$ A. R. Yavari, Acta Metall. Mater. 41, 1391 (1993).

${ }^{11}$ C. Bansal, Z. Q. Gao, L. B. Hong, and B. Fultz, J. Appl. Phys. 76, 5961 (1994).

${ }^{12}$ Z. Q. Gao and B. Fultz, Hyperfine Interact. 94, 2213 (1994); 94, 2361 (1994).

${ }^{13}$ Z. Q. Gao and B. Fultz, Nanostruct. Mater. 4, 939 (1994).

${ }^{14}$ C. Bansal, Z. Q. Gao, and B. Fultz, Nanostruct. Mater. 5, 327 (1995).

${ }^{15}$ F. Cardellini, V. Contini, and G. Mazzone, Scr. Metall. Mater. 32, 641 (1995).

${ }^{16}$ U. Herr, M. Pollack, D. L. Olynick, J. M. Gibson, and R. S. Averback, in Thermodynamics and Kinetics of Phase Transformations, edited by J. S. Im, B. Park, A. L. Greer, and G. B. Stephenson, Mater. Res. Soc. Symp. Proc. Proceedings No. 398 (Materials Research Society, Pittsburgh 1996) p. 575.

${ }^{17}$ P. Scherrer, C. Dimitropoulos, F. Borsa, and S. Rubini, Phys. Rev. B 57, 10462 (1998).

${ }^{18}$ A. Hernando, X. Amils, J. Nogués, S. Surinach, M. D. Baro, and M. R. Ibarra, Phys. Rev. B 58, R11 864 (1998).

${ }^{19}$ S. Gialanella, X. Amils, M. D. Barò, P. Delcroix, G. Le Caër, L. Lutteroti, and S. Surinach, Acta Mater. 46, 3305 (1998).

${ }^{20}$ R. A. Varin, J. Bystrzycki, and A. Calka, Intermetallics 7, 785 (1999); 7, 917 (1999).

${ }^{21}$ K. Reimann and H. E. Schaefer, Nanostruct. Mater. 12, 633 (1999).

${ }^{22}$ H. E. Schaefer, K. Reimann, W. Straub, R. Phillipp, H. Tanimoto, U. Brossmann, and R. Würschum, Mater. Sci. Eng., A 286, 24 (2000)

${ }^{23}$ X. Amils, J. Nogués, S. Surinach, M. D. Baro, M. A. MunozMorris, and D. G. Morris, Intermetallics 8, 805 (2000).

${ }^{24}$ L. Pasquini, A. A. Rempel, R. Würschum, K. Reimann, M. A. Müller, B. Fultz, and H. E. Schaefer, Phys. Rev. B 63, 134114 (2001)

${ }^{25}$ S. Sarkar and C. Bansal, Acta Mater. 49, 1789 (2001).

${ }^{26}$ D. Negri, A. R. Yavari, and A. Deriu, Acta Mater. 47, 4545 (1999).

${ }^{27}$ D. G. Morris, X. Amils, S. Surinach, M. D. Baro, and M. A. Munoz-Morris, Mater. Sci. Forum 360-362, 195 (2001).

${ }^{28}$ K. Reimann, H. J. Fecht, and H. E. Schaefer, Scr. Mater. 44, 1999 (2001).

${ }^{29}$ J. C. Evert and G. Schmitz, Eur. Phys. J. B 17, 391 (2000).

${ }^{30}$ P. Pochet, E. Tominez, L. Chaffron, and G. Martin, Phys. Rev. B 52, 4006 (1995).

${ }^{31}$ B. Fultz, J. Chem. Phys. 88, 3227 (1988).

${ }^{32}$ B. Fultz and L. Anthony, Philos. Mag. Lett. 59, 237 (1989).

${ }^{33}$ D. Le Floc'h, P. Bellon, and M. Athènes, Phys. Rev. B 62, 3142 (2000).
${ }^{34}$ J. Rodriguez-Carvajal, computer program FULLPROF, Laboratoire Léon Brillouin CEA-CNRS, Grenoble, France, 1998; Physica B 192, 55 (1993).

${ }^{35}$ B. E. Warren, X-Ray Diffraction (Dover, New York, 1990).

${ }^{36}$ B. Fultz and J. M. Howe, Transmission Electron Microscopy and Diffractometry of Materials (Springer-Verlag, Heidelberg, 2001).

${ }^{37}$ G. Le Caër and J. M. Dubois, J. Phys. E 12, 1083 (1979).

${ }^{38}$ M. L. Bhatia, A. K. Singh, and T. K. Nandy, Intermetallics 6, 141 (1998).

${ }^{39}$ R. W. Cahn, Intermetallics 7, 1089 (1999).

${ }^{40}$ R. E. Hanneman and A. N. Mariano, Trans. Metall. Soc. AIME 230, 937 (1964).

${ }^{41}$ L. S. J. Peng and G. S. Collins, Mater. Sci. Forum 235-238, 535 (1997).

${ }^{42}$ T. Naohara and K. Shinohara, Trans. Jpn. Inst. Met. 28, 273 (1987).

${ }^{43}$ W. J. Kitchingman, Acta Crystallogr., Sect. A: Cryst. Phys., Diffr., Theor. Gen. Crystallogr. 24, 282 (1968).

${ }^{44}$ B. F. O. Costa, G. Le Caër, and N. Ayres de Campos, Phys. Status Solidi A 183, 235 (2001).

${ }^{45}$ http://www.ncnr.nist.gov/resources/n-lengths/; Neutron News 3, 29 (1992).

${ }^{46}$ M. V. Nevitt and A. T. Aldred, J. Appl. Phys. 34, 463 (1963).

${ }^{47}$ J. C. Krause, C. Paduani, J. Schaff, and M. I. da Costa Jr., Phys. Rev. B 57, 857 (1998).

${ }^{48}$ Y. Kakehashi, Phys. Rev. B 32, 3035 (1985).

${ }^{49}$ J. C. Krause, J. Schaf, M. I. da Costa, Jr., and C. Paduani, Phys. Rev. B 61, 6196 (2000).

${ }^{50}$ M. Shiga and Y. Nakamura, J. Phys. F: Met. Phys. 8, 177 (1978).

${ }^{51}$ N. Kataoka, K. Sumiyama, and Y. Nakamura, Trans. Jpn. Inst. Met. 27, 823 (1986).

${ }^{52}$ T. Ziller, Ph.D. thesis, Institut National Polytechnique de Lorraine, Nancy, 2000.

${ }^{53}$ G. K. Wertheim, V. Jaccarino, J. H. Wernick, and D. N. E. Buchanan, Phys. Rev. Lett. 12, 24 (1964).

${ }^{54}$ I. Vincze and I. A. Campbell, J. Phys. F: Met. Phys. 3, 647 (1973).

${ }^{55}$ M. B. Stearns, Phys. Rev. B 13, 1183 (1976).

${ }^{56}$ S. M. Dubiel and W. Zinn, J. Magn. Magn. Mater. 37, 237 (1983).

${ }^{57}$ B. Fultz, in Mössbauer Spectroscopy Applied to Magnetism and Materials Science, edited by G. J. Long and F. Grandjean (Plenum, New York, 1993), Vol. 1, p. 1.

${ }^{58}$ Y. Sumitomo, T. Moriya, H. Ino, and F. E. Fujita, J. Phys. Soc. Jpn. 35, 461 (1973).

${ }^{59}$ P. Delcroix, T. Ziller, C. Bellouard, and G. Le Caër, Mater. Sci. Forum 360-362, 329 (2001).

${ }^{60}$ D. Gratias and P. Cénédèse, J. Phys. Colloq. 46, C9-149 (1985). 